\title{
Single photon emission tomography imaging in parkinsonian disorders: a review
}

\author{
Paul D. Acton* and P. David Mozley \\ Department of Radiology, University of Pennsylvania, \\ Philadelphia, PA, USA
}

Parkinsonian symptoms are associated with a number of neurodegenerative disorders, such as Parkinson's disease, multiple system atrophy and progressive supranuclear palsy. Pathological evidence has shown clearly that these disorders are associated with a loss of neurons, particularly in the nigrostriatal dopaminergic pathway.

Positron emission tomography (PET) and single photon emission tomography (SPECT) now are able to visualise and quantify changes in cerebral blood flow, glucose metabolism, and dopaminergic function produced by parkinsonian disorders. Both PET and SPECT have become important tools in the differential diagnosis of these diseases, and may have sufficient sensitivity to detect neuronal changes before the onset of clinical symptoms. Imaging is now being utilised to elucidate the genetic contribution to Parkinson's disease, and in longitudinal studies to assess the efficacy and mode of action of neuroprotective drug and surgical treatments.

This review summarises recent applications of SPECT imaging in the study of parkinsonian disorders, with particular reference to the increasing role it is playing in the understanding, diagnosis and management of these diseases.

\section{Introduction}

Parkinson's disease (PD) (paralysis agitans) is a neurodegenerative disorder which affects over one million people in North America, and is associated with clinical symptoms of motor deficit, such as tremor, rigidity, hypokinesia and bradykinesia [101]. It is one of a family of such diseases associated with the loss of centralnervous system neurons, such as progressive supranuclear palsy (PSP) and multiple system atrophy (MSA).

* Correspondence to: Paul D. Acton, Ph.D., Department of Radiology University of Pennsylvania, 3700 Market Street, Room 305, Philadelphia, PA 19104, USA. Tel.: +1 215349 8374; Fax: +1 215 349 5035; E-mail: pacton@sunmac.spect.upenn.edu.
Discrimination of these diseases is important as each has a different prognosis, requiring distinct treatment regimens, particularly early in the course of the disease [127].

Post-mortem studies have indicated clearly that these parkinsonian disorders exhibit dramatic losses of various neurons, particularly the dopaminergic neurotransmitter system in the nigrostriatum $[63,71]$. The predominant cause of parkinsonism is PD, accounting for up to $85 \%$ of all reported cases. Pathological findings show that early in PD the majority of neuronal loss takes place in the ventrolateral tier of the substantia nigra, which projects to the posterior putamen [48]. This leaves the ventral putamen and caudate relatively spared in the early stages of the disease. In addition, PD is characterised by the formation of neuronal Lewy bodies.

MSA accounts for up to $10 \%$ of patients presenting with parkinsonian symptoms. It exhibits much more widespread disruptions in the brain, with symptoms associated with extrapyramidal, pyramidal, autonomic and cerebellar involvement, and is characterised by degeneration and gliosis in the brain stem, spinal cord, striatum, globus pallidus and cerebellum [126,133]. While most MSA patients do not respond to dopaminergic therapy, the disease exhibits neurodegeneration in the nigrostriatum similar to that observed in PD.

The neuronal loss in PSP is also comparable to PD, but without the formation of Lewy bodies. Degeneration occurs primarily in the brain stem and striatum, with the formation of neurofibrillary tangles [125].

Other important confounds in the differential diagnosis of PD include dopa-responsive dystonia and essential tremor. Dopa-responsive dystonia is an inherited disorder which presents with clinical symptoms very similar to early-onset PD [118]. However, PET and SPECT studies have shown either normal or only slight reductions in dopaminergic function, which is in marked contrast to PD [33,61,116,119,155]. Essential tremor presents with clinical symptoms of postural tremor of approximately $7 \mathrm{~Hz}$, usually involving the hands or forearms. Some similarities between the clin- 
ical symptoms of PD and essential tremor can lead occasionally to misdiagnosis, although PET and SPECT studies have shown clearly there is no loss of dopaminergic neurons in patients with essential tremor $[13,26$, 88].

Until recently, positron emission tomography (PET) and single-photon emission tomography (SPECT) imaging in neurodegenerative disorders have focussed on providing differential diagnosis between patients and healthy control subjects, and also between the different types of parkinsonian disorders. Indeed, it may be that the differential diagnosis of neurodegenerative diseases will provide the first routine clinical application for neuroreceptor and transporter binding studies. However, more recently, imaging studies are becoming increasingly important in understanding the pathogenesis of neurodegenerative disease, and in deciphering any genetic contribution to these disorders. In addition, they are being utilised in longitudinal studies to assess the efficacy of surgical and neuroprotective therapies.

This review discusses the contributions of PET and SPECT imaging on the diagnosis, understanding, and management of parkinsonian disorders, with particular emphasis on SPECT. Although PET has been used for longer and in more applications than SPECT, singlephoton imaging is beginning to make important advances in the field, and in those applications where PET still dominates, the potential contributions from SPECT have been described.

\section{Imaging in the differential diagnosis of parkinsonian disorders}

The differential diagnosis of the various parkinsonian disorders based on clinical symptoms alone is difficult $[57,134,161]$. Tremor is a classic feature of PD, although this can also be found in patients with PSP and MSA. Similarly, a general criteria for diagnosing PD is a good, sustained response to levodopa (L-DOPA) therapy, although, again, this is also found in some patients with MSA and dopa-responsive dystonia. Post mortem studies have shown that the clinical diagnosis of Parkinson's disease is incorrect in almost half the cases diagnosed by general neurologists. The error rate is still thought to exceed $25 \%$ when the diagnosis is made by a subspecialist in movement disorders. These observations, which do not appear to be disputed by practicing clinicians, have contributed to the motivation for developing functional neuroimaging techniques that can differentiate between these disorders.
Structural changes induced by parkinsonian diseases are generally small, and often only evident when the disease is into an advanced stage. Consequently, the diagnostic accuracy of anatomical imaging modalities (e.g. magnetic resonance imaging, MRI) in neurodegenerative disorders is poor [145]. In general, PET and SPECT imaging have provided a better platform for the diagnosis of parkinsonian disorders. Functional imaging of neurodegenerative disease with PET and SPECT has followed two main paths; studies of blood flow and cerebral metabolism to detect abnormal tissue functioning, or imaging of the dopaminergic neurotransmitter system to study the loss of dopamine neurons.

PET studies of cerebral glucose metabolism have used the glucose analogue $\left[{ }^{18} \mathrm{~F}\right]$ fluorodeoxyglucose ([ $\left.\left.{ }^{18} \mathrm{~F}\right] \mathrm{FDG}\right)$, while the SPECT tracers [ $\left.{ }^{99 \mathrm{~m}} \mathrm{Tc}\right]$ hexamethylpropylene amine oxime ([ $\left.\left.{ }^{99 \mathrm{~m}} \mathrm{Tc}\right] \mathrm{HMPAO}\right)$ and $\left[{ }^{99 \mathrm{~m}} \mathrm{Tc}\right]$ ethylcysteinate dimer $\left(\left[{ }^{99 \mathrm{~m}} \mathrm{Tc}\right] \mathrm{ECD}\right)$ are markers of cerebral perfusion. Striatal glucose metabolism and perfusion are generally found to be normal in PD [75,100,122,154,172], although some studies have demonstrated an asymmetry of striatal metabolism [38]. Interestingly, atypical parkinsonian disorder has been differentiated from idiopathic PD by the appearance of striatal metabolic abnormalities in the atypical group [6]. Many studies have shown more global cortical hypometabolism or hypoperfusion, or a loss of posterior parietal metabolism with a pattern similar to that observed in Alzheimer's disease [42,93,100, $130,172]$. Others have used the differences in regional metabolism or cerebral blood flow to discriminate between PD and MSA [122,123] or PSP [37]. However, in general, the diagnostic accuracy of cerebral blood flow and glucose metabolism in differentiating neurodegenerative disorders is relatively poor in comparison to direct imaging of the dopaminergic nigrostriatal pathway. This may be particularly true in Parkinson's patients with dementia. Studies of blood flow and glucose metabolism in patients with pure Lewy body disease with no features of Alzheimer's disease have consistently shown bi-parietal, bi-temporal hypometabolism, a pattern that was once thought to represent the signature of Alzheimer's.

A variety of tracers exist for the study of the dopaminergic neurotransmitter system using both PET and SPECT (see Table 1). Early PET studies of the nigrostriatal pathway used the uptake of $6-\left[{ }^{18} \mathrm{~F}\right]$ fluoroL-3,4-dihydroxyphenylalanine ([ $\left.\left.{ }^{18} \mathrm{~F}\right] \mathrm{DOPA}\right)$ as a measure of the integrity of dopamine neurons [51,52]. $\left[{ }^{18} \mathrm{~F}\right]$ DOPA measures changes in striatal dopa decarboxylase activity, which is dependent on the availabil- 
Table 1

Selected PET and SPECT tracers for imaging the dopaminergic neurotransmitter system

\begin{tabular}{llll}
\hline Binding site & Tracer & PET or SPECT & References \\
Dopamine synthesis & {$\left[{ }^{18} \mathrm{~F}\right] \mathrm{DOPA}$} & PET & {$[51,52]$} \\
$\begin{array}{l}\text { Dopamine } \\
\text { transporters }\end{array}$ & {$\left[{ }^{11} \mathrm{C}\right]$ cocaine } & PET & {$[50]$} \\
& {$\left[{ }^{11} \mathrm{C}\right]\left[{ }^{18} \mathrm{~F}\right]\left[{ }^{123} \mathrm{I}\right] \beta$-CIT } & Both & {$[117]$} \\
& {$\left[{ }^{11} \mathrm{C}\right]\left[{ }^{18} \mathrm{~F}\right]\left[{ }^{123} \mathrm{I}\right] \mathrm{FP}-\mathrm{CIT}$} & Both & {$[96]$} \\
& {$\left[{ }^{123} \mathrm{I}\right] \mathrm{IPT}$} & SPECT & {$[82]$} \\
& {$\left[{ }^{123} \mathrm{I}\right]$ altropane } & SPECT & {$[95]$} \\
& {$\left[{ }^{11} \mathrm{C}\right] \mathrm{CFT}$} & PET & {$[34]$} \\
& {$\left[{ }^{11} \mathrm{C}\right]$ methylphenidate } & PET & {$[170]$} \\
Dopamine & {$\left[{ }^{99} \mathrm{Tc}\right] \mathrm{TRODAT}-1$} & SPECT & {$[80,83]$} \\
$\mathrm{D}_{2}$ receptors & {$\left[{ }^{123} \mathrm{I}\right] \mathrm{IBZM}$} & SPECT & {$[78,79,81]$} \\
& {$\left[{ }^{123} \mathrm{I}\right] \mathrm{IBF}$} & SPECT & {$[14,84]$} \\
& {$\left[{ }^{123} \mathrm{I}\right]$ epidepride } & SPECT & {$[67,68]$} \\
& {$\left[{ }^{11} \mathrm{C}\right]$ raclopride } & PET & {$[43]$} \\
& {$\left[{ }^{11} \mathrm{C}\right]\left[{ }^{18} \mathrm{~F}\right] \mathrm{N}$-methylspiroperidol } & PET & {$[10,151]$} \\
\hline
\end{tabular}

ity of striatal dopaminergic nerve terminals and is proportional to the number of dopamine neurons in the substantia nigra [156].

Direct measurements of dopamine transporter binding sites are possible with $\left[{ }^{11} \mathrm{C}\right]$ cocaine [50], or the cocaine analogues $2 \beta$-carbomethoxy-3 $\beta$-[4-iodophenyl] tropane $(\beta$-CIT) and $\mathrm{N}-\omega$-fluoropropyl- $2 \beta$-carbomethoxy-3 $\beta$-[4-iodophenyl] tropane (FP-CIT), labelled with either ${ }^{18} \mathrm{~F}$ or ${ }^{11} \mathrm{C}$ for PET or ${ }^{123} \mathrm{I}$ for SPECT [96, 117]. Other dopamine transporter ligands include $\mathrm{N}$-[3iodopropen-2-yl]-2 $\beta$-carbomethoxy-3 $\beta$-[4-chlorophenyl] tropane ([ $\left.\left.{ }^{123} \mathrm{I}\right] \mathrm{IPT}\right)$ [82], its 4-fluorophenyl analogue $\left[{ }^{123} \mathrm{I}\right]$ altropane [95], $2 \beta$-carbomethoxy- $3 \beta$-[4fluorophenyl] tropane $\left(\left[{ }^{11} \mathrm{C}\right] \mathrm{CFT}\right)[34]$, and $\left[{ }^{11} \mathrm{C}\right] \mathrm{d}-$ threo-methylphenidate [170]. Of particular importance is the recent development of the first successful ${ }^{99 \mathrm{~m}} \mathrm{Tc}$-labeled dopamine transporter ligand, $\left[{ }^{99 \mathrm{~m}} \mathrm{Tc}\right] \mathrm{Technetium}[2-[[2-[[[3-(4-c h l o r o p h e n y l)-$ 8-methyl-8-azabicyclo[3.2.1] oct-2-yl]-methyl](2-mercaptoethyl) amino]-ethyl] amino] ethane-thiolato(3-)N2,N2',S2,S2'] oxo-[1R-(exo-exo)] ([ ${ }^{99 m}$ Tc]TRODAT1) $[80,83]$. Since ${ }^{99 \mathrm{~m}} \mathrm{Tc}$ is so much more widely available and less expensive than ${ }^{123} \mathrm{I}$, this new tracer could move imaging of the dopaminergic system from a research environment into routine clinical practice, particularly with simplified imaging protocols [1].

Several tracers exist for imaging postsynaptic dopamine $\mathrm{D}_{2}$ receptors, using radioactively labelled dopamine receptor antagonists. The most widely used for SPECT include S-(-)-3-iodo-2-hydroxy-6-methoxy-N[(1-ethyl-2-pyrrolidinyl) methyl] benzamide ([ $\left.{ }^{123} \mathrm{I}\right]$ IBZM) [78,79,81], S-5-iodo-7-N-[(1-ethyl-2-pyrrolidinyl) methyl] carboxamido-2,3-dihydrobenzofuran ([ $\left.\left.{ }^{123} \mathrm{I}\right] \mathrm{IBF}\right)[14,84]$, S-N-[(1-ethyl-2-pyrrolidinyl) methyl]-5-iodo-2,3-dimethoxybenzamide ([ ${ }^{123}$ I]epide- pride) $[67,68]$ and for PET include S-(-)-3,5-dichloro$\mathrm{N}$-[(1-ethyl-2-pyrrolidinyl)] methyl-2-hydroxy-6-methoxybenzamide $\left(\left[{ }^{11} \mathrm{C}\right]\right.$ raclopride) $[43]$ and $\left[{ }^{11} \mathrm{C}\right]$ or $\left[{ }^{18} \mathrm{~F}\right] \mathrm{N}$-methylspiroperidol $[10,151]$.

PET and SPECT studies of radiotracer binding to postsynaptic dopamine receptors and presynaptic dopamine transporters and neurons have proved to be powerful techniques for quantifying the loss of dopaminergic neurons in normal aging $[7,35,102,112$, $113,142,166,169,171]$, PD [12,18,19,21,23,25,49,69, $89,114,115,149,159,160,164]$ and other neurodegenerative disorders $[8,28,31,56,59,105,131,165]$ (see Table 2). Studies of neuronal degeneration associated with the effects of normal aging have indicated that, while dopamine transporter concentrations decrease as a natural consequence of aging, the changes are small compared with the effects of disease (Fig. 1) [112]. PET and SPECT studies have indicated a consistent pattern of dopaminergic neuronal loss in PD, usually with more pronounced depletion in the putamen rather than in the caudate (Figs 2 and 3). In addition, there is frequently a marked asymmetry, particularly in the early stages of the disease, and a g ood correlation with symptom severity [159] and illness duration [114]. Most importantly, imaging studies may be sensitive enough to detect very early PD $[18,109,163]$, perhaps even before clinical symptoms become apparent.

Characteristically, PD begins with unilateral symptoms of motor deficit, which gradually progress bilaterally over time. Studies of patients with early hemiPD have shown that, despite the subject only exhibiting one-sided clinical symptoms, the PET and SPECT findings demonstrated bilateral decreases in tracer binding, with a greater reduction in the side contralateral to the clinical signs $[2,18,99,135]$. The ability of PET and 
Table 2

Summary of PET and SPECT measurements of neurodegenerative and parkinsonian disorders

\begin{tabular}{lllll}
\hline & \multicolumn{3}{c}{$\begin{array}{c}\text { Integrity of the dopaminergic nigrostriatal pathway } \\
\text { determined by PET or SPECT }\end{array}$} \\
\cline { 2 - 5 } Syndromes & $\begin{array}{l}\text { Dopamine } \\
\text { transporters } \\
\text { in caudate }\end{array}$ & $\begin{array}{l}\text { Dopamine } \\
\text { transporters } \\
\text { in putamen }\end{array}$ & $\begin{array}{l}\text { Postsynaptic } \\
\text { dopamine } \\
\text { receptors }\end{array}$ & $\begin{array}{l}\text { Blood flow } \\
\text { and } \\
\text { metabolism }\end{array}$ \\
\hline $\begin{array}{l}\text { Parkinson's } \\
\text { disease }\end{array}$ & $\begin{array}{l}\text { Normal or } \\
\text { slight loss }\end{array}$ & Loss & $\begin{array}{l}\text { Normal or } \\
\text { upregulated }\end{array}$ & $\begin{array}{l}\text { General } \\
\text { reduction }- \\
\text { striatum } \\
\text { normal }\end{array}$ \\
$\begin{array}{l}\text { Multiple } \\
\text { system } \\
\text { atrophy }\end{array}$ & $\begin{array}{l}\text { Normal or } \\
\text { slight loss }\end{array}$ & Loss & Loss & $\begin{array}{l}\text { Reduced in } \\
\text { contralateral } \\
\text { putamen }\end{array}$ \\
$\begin{array}{l}\text { Progressive } \\
\text { supranuclear } \\
\text { palsy }\end{array}$ & Loss & Loss & Normal or & $\begin{array}{l}\text { Reduced in } \\
\text { cortex and } \\
\text { striatum }\end{array}$ \\
$\begin{array}{l}\text { Dopa- } \\
\text { responsive } \\
\text { dystonia }\end{array}$ & Normal & Normal & Increase & $? ?$ \\
$\begin{array}{l}\text { MPTP } \\
\text { exposure }\end{array}$ & Loss & Loss & Loss in & $?$ \\
$\begin{array}{l}\text { Essential } \\
\text { tremor }\end{array}$ & Normal & Normal & caudate? & $?$ \\
\hline
\end{tabular}

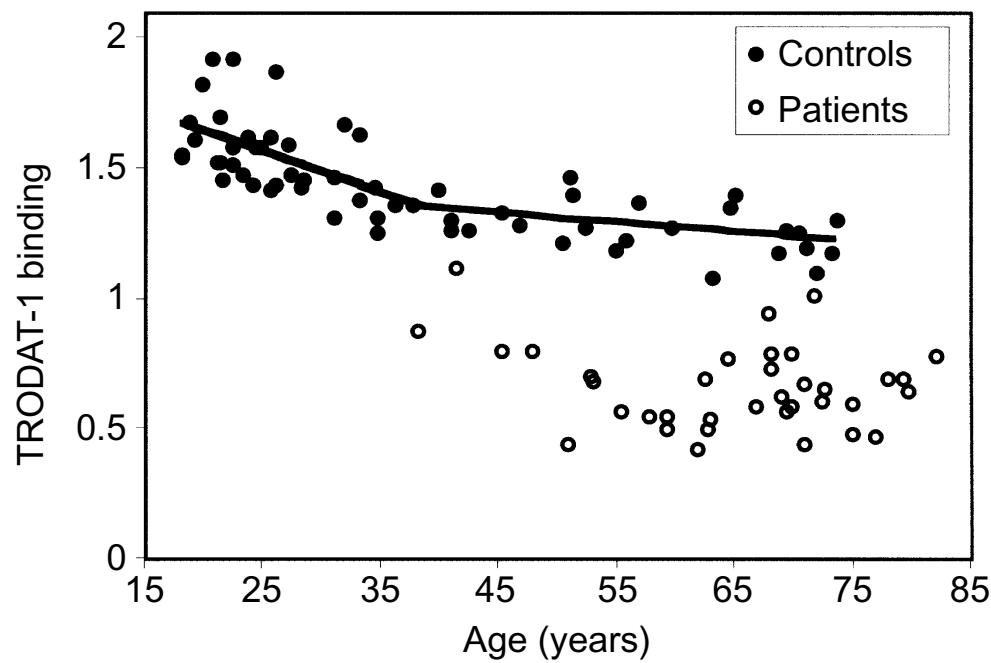

Fig. 1. Age-related decline in the concentrations of dopamine transporters in the striatum, compared with the much greater loss of transporters due to Parkinson's disease, measured with $\left[{ }^{99 \mathrm{~m}}\right.$ Tc]TRODAT-1 and SPECT [112]. The straight line represents a "broken-stick" model fit to the control data, indicating that the loss of dopamine transporters with normal aging occurs in two distinct phases, with a break-point age around 36 years.

SPECT to detect presymptomatic PD may have important consequences for screening of familial PD, and also in the measurement of the efficacy of neuroprotective therapies.

Although most of the PET and SPECT imaging studies have shown highly significant differences between groups of Parkinson's patients and age-matched normal controls, the statistically significant differential diagnosis of an individual subject is more problematic. Patients with severe PD are easily separated from healthy controls even from a simple visual inspection of striatal images, which can be quantified using some form of discriminant analysis [31,114,143,163], which has a sensitivity and specificity close to $100 \%$ in the proper 


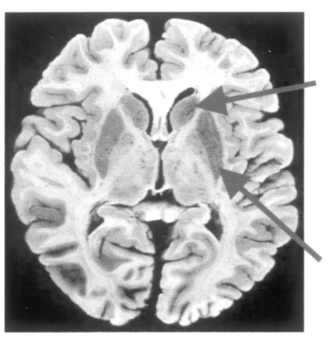

Histology

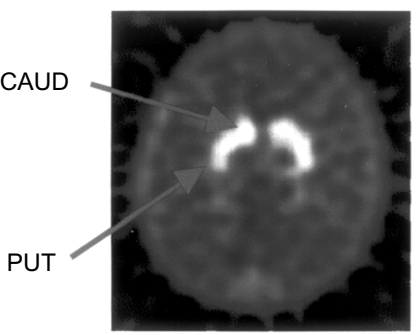

Healthy subject

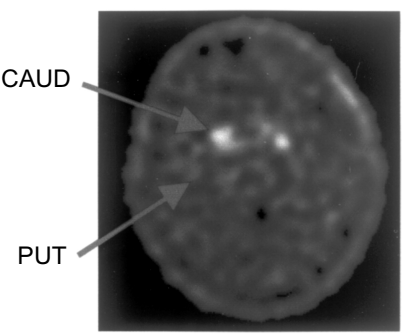

Parkinson's patient

Fig. 2. Transverse SPECT images of [ ${ }^{99 \mathrm{~m}}$ Tc]TRODAT-1 binding to dopamine transporters in human subjects [114]. Left: histology slice through the brain at the level of the striatum to show the head of the caudate nucleus (CAUD) and the putamen (PUT). Centre: transverse SPECT image at the same level from a healthy subject, showing high concentrations of $99 \mathrm{~m}$ Tc]TRODAT- 1 binding to dopamine transporters in the caudate and putamen. Right: SPECT image at the same level in a patient with bilateral Parkinson's disease, showing significant reductions of $\left[{ }^{99 \mathrm{~m}} \mathrm{Tc}\right]$ TRODAT-1 binding in the putamen, but with the caudate relatively spared.

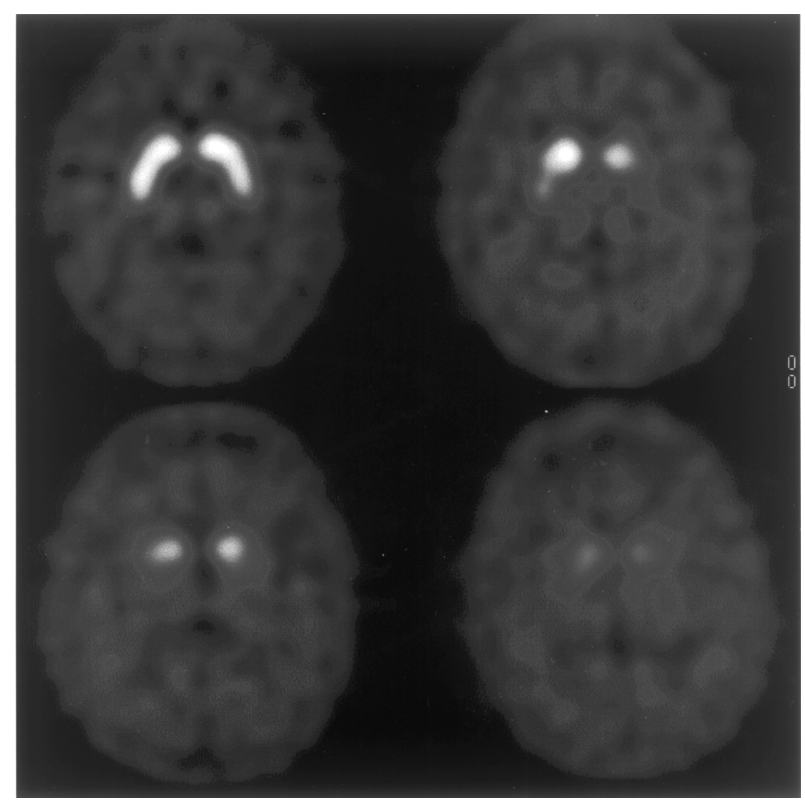

Fig. 3. SPECT images of [ ${ }^{123}$ I]FP-CIT binding to dopamine transporters in a normal healthy control subject (top left) and patients at progressively more severe stages of PD (image courtesy of Dr. Jim Patterson, Institute of Neurological Sciences, Glasgow).

clinical setting. However, patients presenting much earlier in the course of the disease are more difficult to detect, with potentially significant overlap with an agematched control group [109,138] and consequential loss of diagnostic accuracy. The situation may be further complicated if the early differential diagnosis between several neurodegenerative disorders is required. Many of the symptoms associated with parkinsonian disorders are non-specific, which is why the accurate clinical diagnosis of these diseases is difficult. Indeed, some histopathalogical studies have shown that as many as $25 \%$ of all patients who were diagnosed with PD before death had been misdiagnosed $[57,134]$. Studies have shown little difference between radiotracer binding to dopamine transporters in patients with PD and MSA or PSP [28,31]. Based on current methods of analysis, it appears that the detection of early PD, or the differential diagnosis between various neurodegenerative disorders, may not be possible in individual cases based on imaging of a single neurotransmitter system alone [19]. However, recent developments in the automated, pixel-based analysis of PD may improve the sensitivity of imaging techniques [2,54].

The relative merits of anatomical and functional imaging have been combined in some studies which utilize either several different radiotracers, or data 


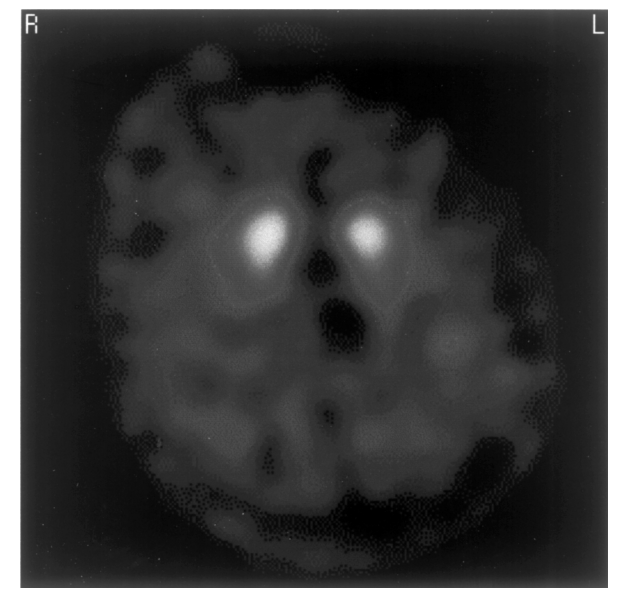

Fig. 4. SPECT image of $\left[{ }^{123}\right.$ I]FP-CIT binding to dopamine transporters in a patient with MSA. Note the similarity between this image and the images of subjects with PD using the same tracer (Fig. 3) which complicates the differential diagnosis (image courtesy of Dr. Jim Patterson, Institute of Neurological Sciences, Glasgow).

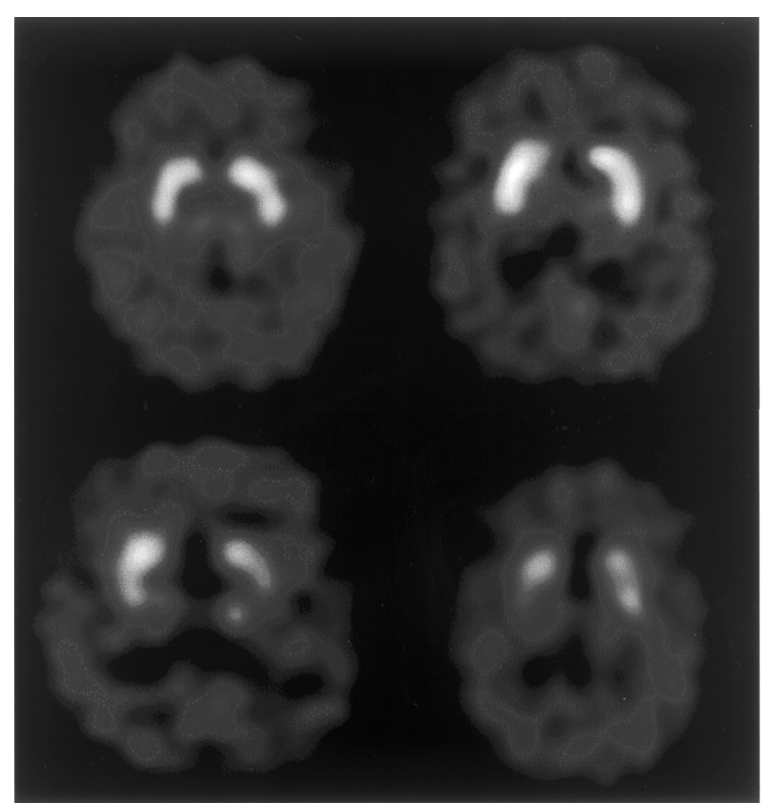

Fig. 5. SPECT images of ${ }^{123}$ I]IBZM binding to postsynaptic dopamine $\mathrm{D}_{2}$ receptors in patients with PD (top row) and MSA (bottom row). Although there is some evidence of striatal degeneration of postsynaptic receptors in MSA, a diagnosis by visual inspection alone can be difficult (image courtesy of Dr. Jim Patterson, Institute of Neurological Sciences, Glasgow).

from both MRI and PET or SPECT. Regional glucose metabolism has been studied in parkinsonian disorders with $\left[{ }^{18} \mathrm{~F}\right] \mathrm{FDG}$ and PET, and the data combined with striatal $\left[{ }^{18} \mathrm{~F}\right]$ fluorodopa uptake measurements to give an improved diagnostic indicator, and a better understanding of the underlying disease processes $[17,44$, 123]. However, it should be noted that the improvement was relatively small over the good predictive capabilities of $\left[{ }^{18} \mathrm{~F}\right]$ fluorodopa by itself in these patient groups. Some studies have utilized the complementary information coming from structural MRI and functional $\left[{ }^{18} \mathrm{~F}\right] \mathrm{FDG}$ PET in distinguishing between patients with MSA and control subjects [62,77], where both focal MRI hypointensities and reduced glucose metabolism occurred on the side contralateral to clinical symptoms. Other studies have combined data from MRI and postsynaptic dopamine receptor concentrations using $\left[{ }^{123} \mathrm{I}\right] \mathrm{IBZM}$ and SPECT, giving useful in- 
formation on the involvement of multiple brain regions in PSP [11] and MSA [146].

However, the greatest discrimination between various neurodegenerative disorders may be found using PET or SPECT imaging of both pre-and postsynaptic dopamine binding sites. A study of $\left[{ }^{123} \mathrm{I}\right] \beta$-CIT and $\left[{ }^{123}\right.$ I]IBZM binding in patients with early PD showed marked unilateral reductions in dopamine transporters measured by $\left[{ }^{123} \mathrm{I}\right] \beta$-CIT concomitant with elevated dopamine $\mathrm{D}_{2}$ receptor binding of [ $\left.{ }^{123} \mathrm{I}\right] \mathrm{IBZM}$ [174]. Recent SPECT studies investigating pre-and postsynaptic dopamine binding sites in the differential diagnosis of PD, MSA and PSP have shown promising results, with a reduction in dopamine transporter availability in all diseases, and some discrimination between disorders in the pattern of dopamine $\mathrm{D}_{2}$ receptor concentrations [70] (Figs 4 and 5). Similar results were observed in a PET study of early Parkinson's patients, where striatal $\left[{ }^{18} \mathrm{~F}\right]$ fluorodopa uptake was reduced and $\left[{ }^{11} \mathrm{C}\right]$ raclopride binding was upregulated, with the degree of increase in dopamine receptor binding inversely proportional to disease severity [9]. This study also used $\left[{ }^{18} \mathrm{~F}\right] \mathrm{FDG}$ imaging of the same patients to determine the optimum combination of neuroreceptor function and glucose metabolism to differentiate between healthy controls, and patients with PD [9] or MSA [8]. The results suggest that striatal $\left[{ }^{18} \mathrm{~F}\right] \mathrm{FDG}$ and particularly $\left[{ }^{11} \mathrm{C}\right]$ raclopride are sensitive to striatal function and may help with the characterization of patients with MSA, whereas $\left[{ }^{18} \mathrm{~F}\right]$ fluorodopa can accurately detect nigrostriatal dopaminergic abnormalities consistent with parkinsonian disorders.

SPECT imaging of both pre- and postsynaptic dopamine binding sites simultaneously has now been performed in non-human primates, using [ $\left.{ }^{99 \mathrm{~m}} \mathrm{Tc}\right]$ TRODAT- 1 and $\left[{ }^{123}\right.$ I]IBZM, separating the two radiotracers based on their different energy spectra [40]. The possibility of simultaneously imaging both dopamine transporters and $\mathrm{D}_{2}$ receptors in neurodegenerative disorders is an exciting prospect, providing a unique probe in the investigation and diagnosis of these diseases.

\section{Longitudinal imaging studies in parkinsonian disorders}

The majority of PET and SPECT imaging studies in parkinsonian disorders have concentrated on differentiating between the various diseases. However, more recently, follow-up longitudinal studies of patient groups have been undertaken, providing important in- sights into the rate of progression of disease, and also enabling estimates of the duration of the preclinical phase. Both PET and SPECT imaging have shown they are sufficiently reproducible and sensitive to measure changes in dopaminergic function consistent with the progression of neurodegenerative disease.

Longitudinal PET and SPECT studies have been performed on patients with PD [20,98,107,110,111,148, 167], and MPTP-induced parkinsonian disorder [168]. All longitudinal studies have shown that the rate of deterioration of dopaminergic neurons is much greater in PD than that associated with the effects of normal aging, although the estimates of the mean rate of disease progression vary quite widely. Using PET and $\left[{ }^{18} \mathrm{~F}\right] \mathrm{DOPA}$, the rates of neuronal loss have been estimated to range from $0.5 \%$ of the normal per year [167] up to $7 \%$ of the normal per year [110], although this depends strongly on the method of analysis and the striatal region being studied [107]. Recent SPECT studies have demonstrated relatively consistent reductions in dopamine transporter binding between $7-11 \%$ per year [20,148], although these data are still preliminary. Extrapolating back to the time of onset of clinical symptoms, the magnitude of neuronal loss required before external clinical signs become apparent has been estimated to be $75 \%$ of normal in the putamen, and $91 \%$ of normal in the caudate [107], which is in approximate agreement with studies of the asymptomatic side in hemi-PD [22]. Extrapolating beyond the threshold for clinical symptom onset, the same study estimated that the mean pre-clinical period (the time between disease onset and symptom onset) was less than 7 years [107]. These results have important consequences for models of disease pathogenesis and progression.

\section{Imaging in the pathogenesis of PD}

Many neurotoxins and neurological traumas which damage the basal ganglia and substantia nigra produce clinical symptoms of parkinsonian disorders. One well-known toxin, 1-methyl-4-phenyl-1,2,3,6tetrahydropyridine (MPTP) appears to target with high specificity those neurons that are involved in PD, and has been utilised in animal models of the disease.

The mechanism of MPTP neurotoxicity may shed some light on the pathogenesis of PD and other neurodegenerative disorders [73]. MPTP is highly lipophillic, and crosses the blood-brain barrier where it is oxidised to $\mathrm{MPP}^{+}$. Although MPTP itself does not appear to be toxic, the oxidised product $\mathrm{MPP}^{+}$is 
taken up by the dopamine transporter protein, where it is actively transported into dopaminergic nerve terminals [153]. Once inside the presynaptic neuron, $\mathrm{MPP}^{+}$ is a potent toxin resulting in neuronal cell death.

This mechanism for MPTP neurotoxicity has led to the suggestion that parkinsonian disorders may be caused by other toxins, whether endogenous or acquired from the environment [104]. It may be a predisposition to producing endogenous toxins that introduces a genetic aspect to PD. A prime candidate for these neurotoxins are free radicals, which may cause neuronal injury through a number of mechanisms, including excitotoxicity, metabolic dysfunction, and interference with intracellular calcium $[32,47,60,150]$.

The central role of dopamine reuptake sites in the transport of the toxin into the neuron has been investigated recently, using SPECT imaging of $\left[{ }^{123} \mathrm{I}\right] \beta$-CIT binding in normal controls and patients with PD [148]. It is hypothesised that, if the transport of endogenous toxins by dopamine transporters into the neuron causes cell death, then a patient with a greater initial concentration of functioning transporters should degenerate faster due to the increased uptake of neurotoxins. Consequently, an initial SPECT scan of the concentration of available dopamine reuptake sites should be a good marker for the rate of progression of the disease, monitored by a follow-up scan some time later. This was found to be the case, where among PD patients the reduction in $\left[{ }^{123} \mathrm{I}\right] \beta$-CIT binding in sequential scans was highly correlated with the initial scan $\left[{ }^{123} \mathrm{I}\right] \beta$-CIT uptake [148]. This is the first evidence from in vivo imaging that neurotoxin uptake may be implicated in the pathogenesis of PD.

The genetic contribution to the etiology of neurodegenerative parkinsonian disorders is still unclear, although it is now believed that heredity plays an important role in PD. Early twin studies did not suggest a genetic contribution $[41,173]$. However, it now appears that genetic factors may confer some degree of susceptibility to PD [97], particularly in light of some recent PET studies in twins $[30,128]$ and in families in which clinically asymptomatic relatives of PD sufferers exhibited signs of striatal degeneration [129,144]. These studies have shown very effectively the potential for PET and SPECT screening of subjects at risk from familial PD.

\section{Imaging in the drug treatment of PD}

The management and treatment of PD with dopamine replacement therapies has been tremendously success- ful for many patients. L-DOPA and dopamine receptor agonists are extremely efficacious in reducing the clinical symptoms associated with PD. However, their effectiveness can decrease over time, with the development of some side-effects and the characteristic "onoff" periods [86,87]. Medication refractory periods of severe bradykinesia and rigidity tend to increase in frequency and severity with time [106], and can alternate with disabling dyskinesias and dystonias. While there are a number of promising neuroprotective drugs in development which may delay the onset of these symptoms, about half of all patients begin to suffer from these sequelae in less than five years.

It is the deficit of striatal dopamine that induces the motor symptoms in PD, hence several potential treatment mechanisms operate by increasing the quantity of endogenous dopamine. L-DOPA is the amino acid precursor which is decarboxylated in the synthesis of dopamine in the brain. It has been used for many years to treat PD in the form of dopamine replacement therapy. However, the undesirable side-effects of L-DOPA treatment, together with a gradual decline in its efficacy over time, has led to the development of further drug treatments to either delay the onset of side-effects, or to delay the need for conventional L-DOPA therapy. The main targets of the newer drugs for PD are two important enzymes in the metabolism of dopamine, namely monoamine oxidase-B (MAO-B) and catecholO-methyltransferase (COMT) [15]. The inhibition of dopamine metabolism enhances its availability at postsynaptic receptor sites, reducing or removing the need for L-DOPA replacement therapy. Several MAO-B and COMT inhibitors have been shown clinically to reduce the effects of the classic "on-off" behaviour of L-DOPA therapy, in addition to enhancing its efficacy [127,162]. It has also been suggested that these agents may confer some neuroprotective property, by slowing cell death. Similarly, other neuroprotective agents have been proposed which scavenge the free radicals and reduce or even reverse the effects of neuronal degeneration [29, $58,136,175]$.

However, it is unclear whether these drugs operate solely by enhancing the levels of endogenous dopamine, or by a true neuroprotective quality in slowing down or reversing the degeneration of dopamine neurons [72]. Clinical studies alone cannot determine whether these drugs exhibit genuine neuroprotective properties, or simply increase available dopamine. Indeed, it has been suggested that L-DOPA treatment, despite its clinical efficacy, may actually accelerate the degeneration of the dopaminergic neurons by increas- 
ing the levels of free radicals through dopamine autooxidation [120,121,175], although others have questioned this theory [3]. However, since L-DOPA decreases the clinical signs of PD, it would be very difficult to show clinically that L-DOPA actually does accelerate neuronal cell death.

Consequently, a quantitative means for the in vivo imaging of dopaminergic neurons would provide a vital probe to examine the mode of action and efficacy of various drugs in the treatment of PD. PET and SPECT could be used to determine whether the neuroprotective therapies are genuinely slowing the degeneration of dopaminergic neurons, or simply altering levels of endogenous neurotransmitter [108]. Both PET and SPECT imaging of the dopaminergic system have exquisite sensitivity to detect and measure subtle changes in neuronal integrity, and have been used in longitudinal studies to monitor the progression of disease in PD [20,107,148,167] and other parkinsonian disorders [56]. Comparisons between dopamine $\mathrm{D}_{2}$ receptor availability, measured with [ ${ }^{123}$ I]IBZM SPECT, and long-term clinical follow-up showed a strong correlation between initial $\left[{ }^{123} \mathrm{I}\right] \mathrm{IBZM}$ binding and the response to L-DOPA therapy, and also to the likelihood of developing non-PD clinical symptoms [147]. The ability of SPECT imaging to predict those subjects that will respond to certain therapies is a vital tool in the clinical management and prognosis of patients with PD and other parkinsonian diseases.

There are currently many studies in progress which use these imaging techniques to monitor changes in the dopaminergic system, and soon they will be able to shed some light on the efficacy and neuroprotective qualities of these therapies.

\section{Imaging in the surgical treatment of PD}

Several neurosurgical procedures have been developed over a number of years to treat patients with PD, particularly those who exhibit poor or declining response to conventional L-DOPA drug therapy.

At this time, the most common surgical intervention for the palliation of tremor remains thallidotomy, whereas for the palliation of dyskinesias and off periods it is pallidotomy [85]. Pallidotomy is designed to reduce the hyperactivity in the internal segment of the globus pallidus caused by excessive input from the subthalamic nuclei [153]. This benefits the motor disabilities associated with PD, as it is postulated that striatal dopamine deficiency produces an overactive medial globus pallidus as a result of the disinhibition of glutamatergic projections from the subthalamic nuclei to the globus pallidus. However, the mechanisms underlying the efficacy of pallidotomy are not well understood, and it is also associated with some risk of cognitive and visual morbidity. Imaging studies of patients undergoing pallidotomy have been performed, although they have been limited to measurements of cerebral blood flow [53,140] and metabolism $[4,45,46,66]$ using PET and $\mathrm{H}_{2}{ }^{15} \mathrm{O}$ and ${ }^{18} \mathrm{FDG}$ respe ctively. However, these studies have indicated promising results in the capability of functional imaging to predict the outcome of pallidotomy $[4,66]$, and correlate with the improvements in functional ability $[45,66]$. Future PET and SPECT studies of pre- and post-operative dopaminergic function should refine these results, and give important clues to the nature of the beneficial effects of pallidotomy.

An exciting alternative to pallidotomy is the electrical stimulation of the subthalamus [39,76,90,91,132]. Although the mechanism of action of subthalamic stimulation is not fully understood, it is believed to be conceptually related to pallidotomy, in that the source of overstimulation to the globus pallidus is removed by electrical pulses. Subthalamic stimulation is achieved by the insertion of electrodes into the brain, with an external pulse generator whose frequency and duration can be modulated to suit the individual. This technique is less invasive than pallidotomy, and it is also reversible. However, like any neurosurgical procedure, it involves some degree of risk, such as cognitive degradation in a few patients [76]. Open and double-blind evaluations of the technique suggest that it is capable of slowing the progression of PD [86]. Favorable assessments have been based primarily on subjective descriptions of symptom severity tracked with patient diaries and clinical rating scales [86]. As compelling as these descriptions are, and as useful as these subjective measures have been in assessing changes within patients, there have not been many objective ways of comparing results between groups of patients treated with different operations and protocols, such as variable schedules or stimulation at different frequencies.

A third surgical methodology, developed relatively recently, involves the transplantation of fetal tissue into the nigrostriatal dopaminergic pathway, either using tissue from aborted human fetuses [92] or from animals [36]. The concept behind this technique is that the grafted fetal nigral cells will survive and reinnervate the striatum, replacing the dopaminergic striatal neurons lost in PD. To assess the efficacy of fetal grafts in $\mathrm{PD}$, several studies have used $\left[{ }^{18} \mathrm{~F}\right] \mathrm{DOPA}$ PET to mea- 
sure any increases in dopaminergic function following surgery $[24,74,92,137,141,158]$. While only small numbers of patients have been studied thus far, the utility of PET and, in the future, SPECT in assessing the response to fetal transplant appears very promising.

Clinical measures of the outcome of these surgical techniques have indicated that pallidotomy may have the best results, but some investigators conclude that "the role of surgery in managing other levodoparesistant problems is controversial, and to date there are no convincing reports demonstrating a benefit" [87]. The potential morbidity as well as the costs of these operations require systematic and longitudinal assessments of their efficacy, a role for which PET and SPECT imaging of the dopaminergic system is uniquely capable [24].

\section{Imaging of non-dopaminergic neurons in PD}

Although the majority of studies investigating neuronal changes caused by parkinsonian diseases have focussed on the dopaminergic system, another neurotransmitter is believed to be intimately linked to the pathogenesis of PD, namely glutamate (NMDA) (see [87] for a detailed explanation of the various neurotransmission pathways thought to be involved in PD). NMDA is an excitatory amino acid, and has been implicated as the neurotransmitter which causes excitotoxicity in the pathophysiology of PD [16,55,94,139,157]. NMDA induces excitotoxicity in the presence of impaired cellular energy metabolism, which may be just the environment produced in dopaminergic neurons in the substantia nigra pars compacta by PD. Dopamine deficiency in PD causes disinhibition and overactivity of the subthalamic nuclei, which project to the external and internal segments of the globus pallidus and the substantia nigra. Neurons from the subthalamus are excitatory, using NMDA as a neurotransmitter, and innervate dopaminergic neurons in the substantia nigra pars compacta that contain NMDA receptors. Hence, disinhibition of the subthalamic nuclei neurons caused by PD may induce NMDA excitotoxic damage in target structures, such as the substantia nigra pars compacta. This scenario of dopamine loss augmenting subthalamic activity, which, in turn, causes further NMDAinduced damage to dopamine neurons creates the ideal environment for an increasing cycle of neuronal cell death.

The role of NMDA, and a possible dysfunction of the NMDA receptor in PD makes it an important tar- get for new neuroprotective treatments. In particular, the modulation of NMDA receptor-mediated neurotransmission may provide an exciting alternative to dopaminergic drug therapies $[16,55,94,139]$. However, the role of NMDA receptors in PD requires investigation with imaging techniques to measure any changes in NMDA function as a result of disease, or to study NMDA excitotoxicity as a mechanism in the initial onset of PD.

The development of specific agents for imaging the NMDA receptor is still in its infancy, with just a small number of potential ligands under development for PET and SPECT. $\left[{ }^{11} \mathrm{C}\right]$ ketamine exhibited relatively poor brain uptake in animal studies, probably due to its rapid metabolism [152]. Preliminary results for a recently developed tracer, $\left[{ }^{18} \mathrm{~F}\right] 1$-amino3-fluoromethyl-5-methyl-adamantane ([ $\left.\left.{ }^{18} \mathrm{~F}\right] \mathrm{AFA}\right)$, are much more promising, with high brain uptake in mice and a cerebral distribution consistent with the known concentrations of NMDA receptors [5]. A SPECT tracer, $\left[{ }^{123} \mathrm{I}\right] \mathrm{MK}-801$ also has shown promise, although it exhibits a high degree of non-specific binding due to high lipophilicity [27,124]. However, further NMDA SPECT ligands are currently in the late stages of development [103].

Another neurotransmitter, gamma-aminobutyric acid (GABA), is a major component of the neural pathways involved in motor function. GABA is an inhibitory neurotransmitter, and is involved in the transmission of signals from the striatum to the globus pallidus and into the subthalamic nuclei. It also provides control over the thalamic nuclei and brain stem from the internal globus pallidus and substantia nigra reticulata. Because these structures use the inhibitory neurotransmitter GABA, the increased glutamatergic-driven input resulting from PD causes excessive GABAergic inhibition, which leads to an effective shutdown of the thalamic and brain stem nuclei [87]. This inhibition leads to suppression of the motor cortex and brain stem locomotor areas, which may cause many of the motor deficits inherent in PD.

Despite the widespread and vital role of the GABAergic system in PD, very few imaging studies of the GABA system have been performed. However, a recent Japanese study, using the SPECT ligand $\left[{ }^{123} \mathrm{I}\right]$ iomazenil, demonstrated a pronounced impairment of cortical GABAergic function in PD, with the reduction in $\left[{ }^{123} \mathrm{I}\right]$ iomazenil binding directly correlated with motor disability $[64,65]$. 


\section{Future directions}

There are a large number of imaging techniques which can be used to attempt to differentiate between the various neurodegenerative disorders. Taken in isolation, many of them can diagnose PD, MSA and PSP with some success. However, the diagnosis at an early stage in the progression of each disease, possibly even before clinical symptoms have become apparent, is much more difficult, and may require multiple imaging modalities or combinations of tracers. The widespread availability of SPECT imaging, perhaps combined with newer and less expensive tracers, may lead to the routine implementation of SPECT scanning in the diagnosis of parkinsonian disorders.

Early diagnosis may become increasingly important once the genetic contribution to parkinsonian disorders is fully understood. SPECT imaging is beginning to make important contributions to the understanding of the pathogenesis of PD, and may be able to elucidate the role of other neurotransmitter systems, such as NMDA and GABA, in the onset and progression of PD. The screening of "at-risk" subjects before they present with clinical symptoms may be an effective preventative measure, particularly now neuroprotective therapies are becoming available. Longitudinal studies of patients undergoing treatment, whether by neuroprotective drugs or surgical intervention, will become increasingly important in the assessment of treatment efficacy, and also to determine the exact mode of action of each therapy.

The next few years should provide some important and exciting advances in the understanding and treatment of parkinsonian disorders, and SPECT imaging will play a key role in these investigations.

\section{Acknowledgements}

The authors are indebted to Dr. Jim Patterson of the Institute of Neurological Sciences, Glasgow, Scotland, for kindly providing several SPECT images for this review.

\section{References}

[1] P.D. Acton, S.A. Kushner, M.P. Kung, P.D. Mozley, K. Ploss1 and H.F. Kung, Simplified reference region model for the kinetic analysis of [99mTc]TRODAT-1 binding to dopamine transporters in non-human primates using SPET, European Journal of Nuclear Medicine 26 (1999), 518-526.
[2] P.D. Acton, P.D. Mozley and H.F. Kung, Logistic discriminant parametric mapping: a novel method for the pixel-based differential diagnosis of Parkinson's disease, European Journal of Nuclear Medicine 26 (1999) 1413-1423.

[3] Y. Agid, Levodopa: is toxicity a myth? Neurology 50 (1998), 858-863.

[4] R.L. Alterman, P. Kelley, D. Sterio, E. Fazzini, D. Eidelberg, K. Perrine and A. Beric, Selection criteria for unilateral posteroventral pallidotomy, Acta Neurochirurgica - Supplementum 68 (1997), 18-23.

[5] S.M. Ametamey, S. Samnick, K.L. Leenders, P. Vontobel, G. Quack, C.G. Parsons and P.A. Schubiger, Fluorine-18 radiolabelling, biodistribution studies and preliminary PET evaluation of a new memantine derivative for imaging the NMDA receptor, Journal of Receptor and Signal Transduction Research 19 (1999), 129-141.

[6] A. Antonini, K. Kazumata, A. Feigin, F. Mandel, V. Dhawan, C. Margouleff and D. Eidelberg, Differential diagnosis of parkinsonism with [18F]fluorodeoxyglucose and PET, Movement Disorders 13 (1998), 268-274.

[7] A. Antonini, K.L. Leenders, H. Reist, R. Thomann, H.F. Beer and J. Locher, Effect of age on $\mathrm{D}_{2}$ dopamine receptors in normal human brain measured by positron emission tomography and ${ }^{11}$ C-raclopride, Archives of Neurology 50 (1993), 474-480.

[8] A. Antonini, K.L. Leenders, P. Vontobel, R.P. Maguire, J. Missimer, M. Psylla and I. Gunther, Complementary PET studies of striatal neuronal function in the differential diagnosis between multiple system atrophy and Parkinson's disease, Brain 120 (1997), 2187-2195.

[9] A. Antonini, P. Vontobel, M. Psylla, I. Gunther, P.R. Maguire, J. Missimer and K.L. Leenders, Complementary positron emission tomographic studies of the striatal dopaminergic system in Parkinson's disease, Archives of Neurology 52 (1995), 1183-1190.

[10] C.D. Arnett, A.P. Wolf, C-Y Shiue, J.S. Fowler, R.R. MacGregor, D.R. Christman and M.R. Smith, Improved delineation of human dopamine receptors using $\left[{ }^{18} \mathrm{~F}\right]-\mathrm{N}-$ methylspiroperidol and PET, Journal of Nuclear Medicine 27 (1986), 1878-1882.

[11] G. Arnold, K. Tatsch, W.H. Oertel, T. Vogl, J. Schwarz, E. Kraft and C.M. Kirsch, Clinical progressive supranuclear palsy: differential diagnosis by IBZM-SPECT and MRI, Journal of Neural Transmission 42 (1994), 111-118.

[12] S. Asenbaum, T. Brucke, W. Pirker, I. Podreka, P. Angelberger, S. Wenger, C. Wober, C. Muller and L. Deecke, Imaging of dopamine transporters with iodine-123-beta-CIT and SPECT in Parkinson's disease, Journal of Nuclear Medicine 38 (1997), 1-6.

[13] S. Asenbaum, W. Pirker, P. Angelberger, G. Bencsits, M. Pruckmayer and T. Brücke, [123I]beta-CIT and SPECT in essential tremor and Parkinson's disease, Journal of Neural Transmission 105 (1998), 1213-1228.

[14] J.J. Billings, Y.Z. Guo, M.P. Kung, H.F. Kung, Localization of IBF as a D-2 dopamine receptor imaging agent in nonhuman primates, European Journal of Nuclear Medicine 20 (1993), 1146-1153.

[15] W. Birkmayer, P. Riederer, M.B.H. Youdim and W. Linauer, Potentiation of antikinetic effect after L-dopa treatment by an inhibitor of MAO B, L-deprenyl, Journal of Neural Transmission 36 (1975), 303-323.

[16] F. Blandini, J.T. Greenamyre, Prospects of glutamate antagonists in the therapy of Parkinson's disease, Fundamental and Clinical Pharmacology 12 (1998), 4-12. 
[17] H. Boecker, A. Weindl, K. Leenders, A. Antonini, T. Kuwert, F. Kruggel, H. Grafin von Einsiedel and B. Conrad, Secondary parkinsonism due to focal substantia nigra lesions: a PET study with [18F]FDG and [18F]fluorodopa, Acta Neurologica Scandinavica 93 (1996), 387-392.

[18] J. Booij, G. Tissingh, G.J. Boer, J.D. Speelman, J.C. Stoof, A.G. Janssen, E.C. Wolters and E.A. van Royen, [123I]FPCIT SPECT shows a pronounced decline of striatal dopamine transporter labelling in early and advanced Parkinson's disease, Journal of Neurology, Neurosurgery and Psychiatry 62 (1997), 133-140.

[19] J. Booij, G. Tissingh, A. Winogrodzka and E.A. Royen, Imaging of the dopaminergic neurotransmission system using single-photon emission tomography and positron emission tomography in patients with parkinsonism, European Journal of Nuclear Medicine 26 (1999), 171-182.

[20] J. Booij, A. Winogrodzka, P. Bergmans, E.C. Wolters, J.C. Stoof, E.A. Royen, [I-123]beta-CIT and [I-123]FP-CIT SPECT are useful methods to monitor the progression of dopaminergic degeneration in early stage Parkinson's disease (abstract), Journal of Nuclear Medicine 5(1) (1999), 28.

[21] D.J. Brooks, Detection of preclinical Parkinson's disease with PET, Neurology 41(1) (1991), 24-27.

[22] D.J. Brooks, Detection of preclinical Parkinson's disease with PET, Geriatrics 46(1) (1991), 25-30.

[23] D.J. Brooks, PET and SPECT studies in Parkinson's disease., Baillieres Clinical Neurology 6 (1997), 69-87.

[24] D.J. Brooks, Positron emission tomography studies in movement disorders, Neurosurgery Clinics of North America 9 (1998), 263-282.

[25] D.J. Brooks, V. Ibanez, G.V. Sawle, N. Quinn, A.J. Lees, C.J. Mathias, R. Bannister, C.D. Marsden and R.S.J. Frackowiak, Differing patterns of striatal ${ }^{18}$ F-dopa uptake in Parkinson's disease, multiple system atrophy, and progressive supranuclear palsy, Annals of Neurology 28 (1990), 547.

[26] D.J. Brooks, E.D. Playford, V. Ibanez, G.V. Sawle, P.D. Thompson, L.J. Findley and C.D. Marsden, Isolated tremor and disruption of the nigrostriatal dopaminergic system: an 18F-dopa PET study, Neurology 42 (1992), 1554-1560.

[27] D.R. Brown, D.J. Wyper, J. Owens, J. Patterson, R.C. Kelley, R. Hunter and J. McCulloch, 123Iodo-MK-801: a SPECT agent for imaging the pattern and extent of glutamate (NMDA) receptor activation in Alzheimer's disease, Journal of Psychiatry Research 31 (1997), 605-619.

[28] T. Brucke, S. Asenbaum, W. Pirker, S. Djamshidian, S. Wenger, C. Wober, C. Muller and I. Podreka, Measurement of the dopaminergic degeneration in Parkinson's disease with [123I]beta-CIT and SPECT. Correlation with clinical findings and comparison with multiple system atrophy and progressive supranuclear palsy, Journal of Neural Transmission 50 (1997), 9-24.

[29] G.A. Bubenik, D.E. Blask, G.M. Brown, G.J. Maestroni, S.F. Pang, R.J. Reiter, M. Viswanathan and N. Zisapel, Prospects of the clinical utilization of melatonin, Biological Signals and Receptors 7 (1998), 195-219.

[30] D.J. Burn, M.H. Mark and E.D. Playford, Parkinson's disease in twins studied with [18F]-Dopa and positron emission tomography, Neurology 42 (1992), 1894-1900.

[31] D.J. Burn, G.V. Sawle and D.J. Brooks, Differential diagnosis of Parkinson's disease, multiple system atrophy, and Steele-Richardson-Olszewski syndrome: discriminant analysis of striatal 18F-dopa PET data, Journal of Neurology, Neurosurgery and Psychiatry 57 (1994), 278-284.
[32] J.L. Cadet and C. Brannock, Free radicals and the pathobiology of brain dopamine systems, Neurochemistry International 32 (1998), 117-131.

[33] D.B. Calne, R. de la Fuente-Fernandez and A. Kishore, Contributions of positron emission tomography to elucidating the pathogenesis of idiopathic parkinsonism and dopa responsive dystonia, Journal of Neural Transmission 50 (1997), 47-52.

[34] D.R. Canfield, R.D. Spealman, M.J. Kaufman and B.K. Madras, Autoradiographic localization of cocaine binding sites by $[3 \mathrm{H}] \mathrm{CFT}([3 \mathrm{H}]$ WIN 35,428$)$ in the monkey brain, Synapse 6 (1990), 189-195.

[35] M. Cordes, B.J. Snow, S. Cooper, M. Schulzer, B.D. Pate, T.J. Ruth and D.B. Calne, Age-dependent decline of nigrostriatal dopaminergic function: a positron emission tomographic study of grandparents and their grandchildren, Annals of Neurology 36 (1994), 667-670.

[36] T. Deacon, J. Schumacher, J. Dinsmore, C. Thomas, P. Palmer, S. Kott, A. Edge, D. Penney, S. Kassissieh, P. Dempsey and O. Isacson, Histological evidence of fetal pig neural cell survival after transplantation into a patient with Parkinson's disease, Nature Medicine 3 (1997), 350-353.

[37] L. Defebvre, P. Lecouffe, A. Destee, P. Houdart and M. Steinling, Tomographic measurements of regional cerebral blood flow in progressive supranuclear palsy and Parkinson's disease, Acta Neurologica Scandinavica 92 (1995), 235-241.

[38] S. Dethy, N. Van Blercom, P. Damhaut, D. Wikler, J. Hilderbrand and S. Goldman, Asymmetry of basal ganglia glucose metabolism and dopa responsiveness in parkinsonism, Movement Disorders 13 (1998), 275-280.

[39] J.O. Dostrovsky, K.D. Davis, L. Lee, G.D. Sher and R.R. Tasker, Electrical stimulation-induced effects in the human thalamus, Advances in Neurology 63 (1993), 219-229.

[40] S.H.J. Dresel, M.P. Kung, X.F. Huang, K. Plossl, C. Hou, S.K. Meegalla, G. Patselas, M. Mu, J.R. Saffer and H.F. Kung, Simultaneous SPECT studies of pre-and post-synaptic dopamine binding sites in baboons, Journal of Nuclear Medicine 40 (1999), 660-666.

[41] R.C. Duvoisin, On heredity, twins and Parkinson's disease, Annals of Neurology 19 (1986), 409-411.

[42] J.L. Eberling, B.C. Richardson, B.R. Reed, N. Wolfe and W.J. Jagust, Cortical glucose metabolism in Parkinson's disease without dementia, Neurobiology of Aging 15 (1994), 329335.

[43] E. Ehrin, L. Farde and T. de Paulis, Preparation of 11Clabelled raclopride, a new potent dopamine receptor antagonist: preliminary PET studies of cerebral dopamine receptors in the monkey, International Journal of Applied Radiation and Isotopes 36 (1985), 269-273.

[44] D. Eidelberg, J.R. Moeller, V. Dhawan, J.J. Sidtis, J.Z. Ginos, S.C. Strother, J. Cedarbaum, P. Greene, S. Fahn and D.A. Rottenberg, The metabolic anatomy of Parkinson's disease: complementary $[18 \mathrm{~F}]$ fluordeoxyglucose and [18F]fluorodopa positron emission tomographic studies, Movement Disorders 5 (1990), 203-213.

[45] D. Eidelberg, J.R. Moeller, T. Ishikawa, V. Dhawan, P, Spetsieris, D. Silbersweig, E. Stern, R.P. Woods, E. Fazzini, M. Dogali and A. Beric, Regional metabolic correlates of surgical outcome following unilateral pallidotomy for Parkinson's disease, Annals of Neurology 39 (1996), 450-459.

[46] D. Eidelberg, J.R. Moeller, K. Kazumata, A. Antonini, D. Sterio, V. Dhawan, P. Spetsieris, R. Alterman, P.J. Kelley, M. Dogali, E. Fazzini and A. Beric, Metabolic correlates of pallidal neuronal activity in Parkinson's disease, Brain 120 (1997), 1315-1324. 
[47] F. Facchinetti, V.L. Dawson and T.M. Dawson, Free radicals as mediators of neuronal injury, Cellular and Molecular Neurobiology 18 (1998), 667-682.

[48] J.M. Fearnley and A.J. Less, Aging and Parkinson's disease: substantia nigra regional selectivity, Brain 114 (1991), 22832301.

[49] A.J. Fischman, A.A. Bonab, J.W. Babich, E.P. Palmer, N.M. Alpert, D.R. Elmaleh, R.J. Callahan, S.A. Barrow, W. Graham, P.C. Meltzer, R.N. Hanson and B.K. Madras, Rapid detection of Parkinson's disease by SPECT with altropane: a selective ligand for dopamine transporters, Synapse 29 (1998), 128-141.

[50] J.S. Fowler, N.D. Volkow, A.P. Wolf, S.L. Dewey, D.J. Schlyer, R.R. Macgregor, R. Hitzemann, J. Logan, B. Bendriem and S.J. Gatley, Mapping cocaine binding sites in human and baboon brain in vivo, Synapse 4 (1989), 371-377.

[51] E.S. Garnett, G. Firnau, P.K.H. Chan, S. Sood, L.W. Belbeck, $\left[{ }^{18} \mathrm{~F}\right]$-Fluoro-dopa, an analogue of dopa, and its use in direct external measurements of storage, degradation, and turnover of intracerebral dopamine, Proceedings of the $\mathrm{Na}$ tional Academy of Sciences of the United States of America 75 (1978), 464.

[52] E.S. Garnett, G. Firnau, C. Nahmias, Dopamine visualised in the basal ganglia of living man, Nature 305 (1983), 137.

[53] S.T. Grafton, C. Waters, J. Sutton, M.F. Lew and W. Couldwell, Pallidotomy increases activity of motor association cortex in Parkinson's disease: a positron emission tomographic study, Annals of Neurology 37 (1995), 776-783.

[54] J.B.A. Habraken, J. Boiij, P. Slomka, E.B. Sokole and E.A. van Royen, Quantification and visualization of defects of the functional dopaminergic system using an automated algorithm, Journal of Nuclear Medicine 40 (1999), 1091-1097.

[55] U Heresco-Levy, D.C. Javitt, The role of N-methyl-Daspartate (NMDA) receptor-mediated neurotransmission in the pathophysiology and therapeutics of psychiatric syndromes, European Neuropsychopharmacology 8 (1998), $141-152$.

[56] J. Hierholzer, M. Cordes, S. Venz, L. Schelosky, C. Harisch, W. Richter, U. Keske, N. Hosten, J. Maurer, W. Poewe and R. Felix, Loss of dopamine-D2 receptor binding sites in Parkinsonian plus syndromes, Journal of Nuclear Medicine 39 (1998), 954-960.

[57] A.J. Hughes, S.E. Daniel, S. Blankson and A.J. Lees, A clinicopathalogic study of 100 cases of Parkinson's disease, Archives of Neurology 50 (1993), 140-148.

[58] L. Iacovitti, N.D. Stull and K. Johnston, Melatonin rescues dopamine neurons from cell death in tissue culture models of oxidative stress, Brain Research 768 (1997), 317-326.

[59] N. Ilgin, J. Zubieta, S.G. Reich, R.F. Dannals, H.T. Ravert and J.J. Frost, PET imaging of the dopamine transporter in progressive supranuclear palsy and Parkinson's disease, Neurology 52 (1999), 1221-1226.

[60] P. Jenner, Oxidative mechanisms in nigral cell death in Parkinson's disease, Movement Disorders 13(1) (1998), 24 34.

[61] B.S. Jeon, J.M. Jeong, S.S. Park, J.M. Kim, Y.S. Chang, H.C. Song, K.M. Kim, K.Y. Yoon, M.C. Lee and S.B. Lee, Dopamine transporter density measured by [123I]beta-CIT single photon emission computed tomography is normal in dopa-responsive dystonia, Annals of Neurology 43 (1998), 792-800.

[62] T. Kato, A. Kume, K. Ito, M. Tadokoro, A. Takahashi and S. Sakuma, Asymmetrical FDG-PET and MRI findings of striatonigral system in multiple system atrophy, Radiation Medicine 10 (1992), 87-93.

[63] M.J. Kaufman, B.K. Madras, Severe depletion of cocaine recognition sites associated with the dopamine transporter in Parkinson's diseased striatum, Synapse 49 (1991), 43-49.

[64] K. Kawabata and H. Tachibana, Evaluation of benzodiazepine receptor in the cerebral cortex of Parkinson's disease using 123I-iomazenil SPECT (Japanese), Japanese Journal of Clinical Medicine 55 (1997), 244-248.

[65] K. Kawabata, H. Tachibana, M. Sugita and M. Fukuchi, Impairment of benzodiazepine receptor in Parkinson's disease evaluated by 123I-iomazenil SPECT (Japanese), Japanese Journal of Nuclear Medicine 33 (1996), 391-397.

[66] K. Kazumata, A. Antonini, V. Dhawan, J.R. Moeller, R.L. Alterman, P. Kelly, D. Sterio, E. Fazzini, A. Beric and D. Eidelberg, Preoperative indicators of clinical outcome following stereotaxic pallidotomy, Neurology 49 (1997), 1083-1090.

[67] R.M. Kessler, M.S. Ansari, D.E. Schmidt, T. dePaulis, J.A. Clanton, R.B. Innis, M.S. Al-Tikriti, R.G. Manning and D. Gillespie, High affinity dopamine $\mathrm{D}_{2}$ receptor radioligands. 2. $\left[{ }^{125} \mathrm{I}\right]$ Epidepride, a potent and specific radioligand for the characterization of striatal and extrastriatal dopamine $\mathrm{D}_{2}$ receptors, Life Sciences 49 (1991), 617-628.

[68] R.M. Kessler, N.S. Mason, J.R. Votaw, T. dePaulis, J.A. Clanton, M.S. Ansari, D.E. Schmidt, R.G. Manning and R.E. Bell, Visualization of extrastriatal dopamine D2 receptors in the human brain, European Journal of Pharmacology 223 (1992), 105-107.

[69] H.J. Kim, J.H. Im, S.O. Yang, D.H. Moon, J.S. Ryu, J.K. Bong, K.P. Nam, J.H. Cheon, M.C. Lee and H.K. Lee, Imaging and quantitation of dopamine transporters with iodine123-IPT in normal and Parkinson's disease subjects, Journal of Nuclear Medicine 38 (1997), 1703-1711.

[70] Y.J. Kim, M. Ichise, T. Tatschida, J.R. Ballinger, D. Vines and A.E. Lang, Differential diagnosis of parkinsonism using dopamine transporter and D2 receptor SPECT, Journal of Nuclear Medicine 5(1) (1999), 68.

[71] S.J. Kish, K. Shannak and O. Hornykiewicz, Uneven pattern of dopamine loss in the striatum of patients with idiopathic Parkinson's disease, New England Journal of Medicine 318 (1988), 876-880.

[72] W.C. Koller, Neuroprotective therapy for Parkinson's disease, Experimental Neurology 144 (1997), 24-28.

[73] I.J. Kopin, Features of the dopaminergic neurotoxin MPTP, Annals of the New York Academy of Sciences 648 (1992), 96-104.

[74] J.H. Kordower, T.B. Freeman, E.Y. Chen, E.J. Mufson, P.R. Sanberg, R.A. Hauser, B. Snow and C.W. Olanow, Fetal nigral grafts survive and mediate clinical benefit in a patient with Parkinson's disease, Movement Disorders 13 (1998), 383-393.

[75] D.E. Kuhl, E.J. Metter, W.H. Riege and C.H. Markham, Patterns of cerebral glucose utilisation in Parkinson's disease and Huntingdon's disease, Annals of Neurology 15 (1984), 119-125.

[76] R. Kumar, A.M. Lozano, Y.J. Kim, W.D. Hutchison, E. Sime, E. Halket and A.E. Lang, Double blind evaluation of subthalamic nucleus deep brain stimulation in advanced Parkinson's disease, Neurology 51 (1998), 850-855.

[77] A. Kume, M. Shiratori, A. Takahashi, T. Kato, K. Ito, M. Tadokoro and S. Sakuma, Hemi-parkinsonism in multiple system atrophy: a PET and MRI study, Journal of the Neurological Sciences 110 (1992), 37-45. 
[78] H.F. Kung, A. Alavi, W. Chang, M-P Kung, J.W. Keyes, Jr., M.G. Velchik, J.J. Billings, S. Pan, R. Noto, A. Rausch and J. Reilley, In vivo SPECT imaging of CNS $\mathrm{D}_{2}$ dopamine receptors: initial studies with iodine-123-IBZM in humans, Journal of Nuclear Medicine 31 (1990), 573-579.

[79] H.F. Kung, J.J. Billings, Y-Z Guo, X. Xu, R.H. Mach, M. Blau and R.E. Ackerhalt, Preparation and biodistribution of [ ${ }^{125}$ I]IBZM: a potential $\mathrm{CNS}_{2}$ dopamine receptor imaging agent, Nuclear Medicine \& Biology 15 (1988), 195-201.

[80] H.F. Kung, H-J Kim, M-P Kung, S.K. Meegalla, K. Plössl and $\mathrm{H}-\mathrm{K}$ Lee, Imaging of dopamine transporters in humans with technetium-99m TRODAT-1, European Journal of Nuclear Medicine 23 (1996), 1527-1530.

[81] H.F. Kung, S. Pan, M-P Kung, J.J. Billings, R. Kasliwal, J. Reilly and A. Alavi, In vitro and in vivo evaluation of [ ${ }^{123}$ I]IBZM: a potential $\mathrm{CNS}_{2}$ dopamine receptor imaging agent, Journal of Nuclear Medicine 30 (1989), 88-92.

[82] M-P Kung, W.D. Essman, D. Frederick, S. Meegalla, M. Goodman, M. Mu, I. Lucki and H.F. Kung, IPT: a novel iodinated ligand for the CNS dopamine transporter, Synapse 20 (1995), 316-324.

[83] M-P Kung, D.A. Stevenson, K. Plössl, S.K. Meegalla, A. Beckwith, W.D. Essman, M. Mu, I. Lucki and H.F. Kung, [ $\left.{ }^{99 \mathrm{~m}} \mathrm{Tc}\right]$ TRODAT-1: a novel technetium-99m complex as a dopamine transporter imaging agent, European Journal of Nuclear Medicine 24 (1997), 372-380.

[84] M.P. Kung, H.F. Kung, J. Billings, Y. Yang, R.A. Murphy and A. Alavi, The characterization of IBF as a new selective dopamine D-2 receptor imaging agent, Journal of Nuclear Medicine 31 (1990), 648-654.

[85] L.V. Laiten, A.T. Bergenheim and M.I. Hariz, Leksell's postero-ventral pallidotomy in the treatment of Parkinson's disease, Journal of Neurosurgery 76 (1992), 53-61.

[86] A.E. Lang, A.M. Lozano, Parkinson's disease. First of two parts., New England Journal of Medicine 339 (1998), 1044 1053.

[87] A.E. Lang and A.M. Lozano, Parkinson's disease. Second of two parts., New England Journal of Medicine 339 (1998), $1130-1143$.

[88] M.S. Lee, Y.D. Kim, J.H. Im, H.J. Kim, J.O. Rinne and K.P. Bhatia, 123I-IPT brain SPECT study in essential tremor and Parkinson's disease, Neurology 52 (1999), 1422-1426.

[89] K.L. Leenders, The nigrostriatal dopaminergic system assessed in vivo by positron emission tomography in healthy volunteer subjects and patients with Parkinson's disease, Archives of Neurology 47 (1990), 1290.

[90] P. Limousin, P. Krack, P. Pollak, A. Benazzouz, C. Ardouin, D. Hoffman and A.L. Benabid, Electrical stimulation of the subthalamic nucleus in advanced Parkinson's disease, New England Journal of Medicine 339 (1998), 1105-1111.

[91] P. Limousin, P. Pollak, A. Benazzouz, D. Hoffmann, E. Broussolle, J.E. Perret and A.L. Benabid, Bilateral subthalamic nucleus stimulation for severe Parkinson's disease, Movement Disorders 10 (1995), 672-674.

[92] O. Lindvall, S. Rehncrona, P. Brundin, B. Gustavii, B. Astedt, H. Widner, T. Lindholm, A. Bjorklund, K.L. Leenders and J.C. Rothwell, Human fetal dopamine neurons grafted into the striatum in two patients with severe Parkinson's disease. A detailed account of methodology and a 6-month follow-up, Archives of Neurology 46 (1989), 615-631.

[93] R.S. Liu, K.N. Lin, S.J. Wang, D.E. Shan, J.L. Fuh, S.H. Yeh and H.C. Liu, Cognition and 99mTc-HMPAO SPECT in Parkinson's disease, Nuclear Medicine Communications 13 (1992), 744-748.
[94] L.D. Loopuijt and W.J. Schmidt, The role of NMDA receptors in the slow neuronal degeneration of Parkinson's disease, Amino Acids 14 (1998), 17-23.

[95] B.K. Madras, L.M. Gracz, P.C. Meltzer, A.Y. Liang, D.R. Elmaleh, M.J. Kaufman and A.J. Fischman, Altropane, a SPECT or PET imaging probe for dopamine neurons: II. Distribution to dopamine-rich regions of primate brain, Synapse 29 (1998), 105-115.

[96] B.K. Madras, R.D. Spealman, M.A. Fahey, J.L. Neumeyer, J.K. Saha and R.A. Milius, Cocaine receptors labeled by [3H]2b-carbomethoxy-3b-(4-fluorophenyl)tropane, Molecular Pharmacology 36 (1989), 518-524.

[97] D.M. Maraganore, A.E. Harding and C.D. Marsden, A clinical and genetic study of familial Parkinson's disease, Movement Disorders 6 (1991), 205-211.

[98] K.L. Marek, J.P. Seibyl, B. Fussell, J. Cellar, E. Smith and R.B. Innis, 123I beta-CIT: assessment of progression in Parkinson's disease (abstract), Neurology 48 (1997), A207.

[99] K.L. Marek, J.P. Seibyl, S.S. Zoghbi, Y. Zea-Ponce, R.M. Baldwin, B. Fussell, D.S. Charney, C. Van Dyck, P.B. Hoffer and R.B. Innis, [I-123]beta-CIT SPECT imaging demonstrates bilateral loss of dopamine transporters in hemiParkinson's disease, Neurology 46 (1996), 231-237.

[100] H.S. Markus, A.J. Lees, G. Lennox, C.D. Marsden and D.C. Costa, Patterns of regional cerebral blood flow in corticobasal degenration studied using HMPAO SPECT; comparison with Parkinson's disease and normal controls, Movement Disorders 10 (1995), 179-187.

[101] C.D. Marsden, Parkinson's disease, Journal of Neurology, Neurosurgery and Psychiatry 57 (1994), 672-681.

[102] W.R.W. Martin, M.R. Palmer, C.S. Patlak and D.B. Calne, Nigrostriatal function in man studied with positron emission tomography, Annals of Neurology 26 (1989), 535-542.

[103] J. McCulloch, K.W. Muir, J.R. Owens, D.M. Hadley, D.G. Grosset, G.J. Durant, S. Magar, A.G. Knapp, K. Kodama, A.L. McGregor, D.J. Wyper, A.A. Tebbutt, D.J. Robbins and J. Patterson, Uptake and retention in human CNS of a new NMDA ion channel ligand (abstract), Journal of Cerebral Blood Flow and Metabolism 17 (1997), 132

[104] K.S. McNaught, P.A. Carrupt, C. Altomare, S. Cellamare, A. Carotti, B. Testa, P. Jenner and C.D. Marsden, Isoquinoline derivatives as endogenous neurotoxins in the aetiology of Parkinson's disease, Biochemical Pharmacology 56 (1998), 921-933.

[105] C. Messa, M.A. Volonte, F. Fazio, F. Zito, A. Carpinelli, A. d'Amico, G. Rizzo, R.M. Moresco, E. Paulesu, M. Franceschi and G. Lucignani, Differential distribution of striatal [123I]beta-CIT in Parkinson's disease and progressive supranuclear palsy, evaluated with single photon emission tomography, European Journal of Nuclear Medicine 25 (1998), 1270-1276.

[106] E. Miyawaki, K. Lyons, R. Pahwa, A.I. Troster, J. Hubble, D. Smith, K. Busenbark, D. McGuire, D. Michalek and W.C. Koller, Motor complications of chronic levodopa therapy in Parkinson's disease, Clinical Neuropharmacology 20 (1997), 523-530.

[107] P.K. Morrish, J.S. Rakshi, D.L. Bailey, G.V. Sawle and D.J. Brooks, Measuring the rate of progression and estimating the preclinical period of Parkinson's disease with [18F]dopa PET, Journal of Neurology, Neurosurgery and Psychiatry 64 (1998), 314-319.

[108] P.K. Morrish, J.S. Rakshi and J.D. Brooks, Can the neuroprotective efficacy of an agent ever be conclusively proven? European Journal of Neurology 4(3) (1997), S19-24. 
[109] P.K. Morrish, G.V. Sawle and D.J. Brooks, Clinical and [18F]dopa PET findings in early Parkinson's disease, Journal of Neurology, Neurosurgery and Psychiatry 59 (1995), 597-600.

[110] P.K. Morrish, G.V. Sawle and D.J. Brooks, An [18F]dopaPET and clinical study of the rate of progression in Parkinson's disease, Brain 119 (1996), 585-591.

[111] P.K. Morrish, G.V. Sawle and D.J. Brooks, The rate of progression of Parkinson's disease. A longitudinal [18F]DOPA PET study, Advances in Neurology 69 (1996), 427-431.

[112] P.D. Mozley, P.D. Acton, E.D. Barraclough, K. Plossl, R.C. Gur, A. Mathur, A. Alavi, J. Saffer and H.F. Kung, Effects of age on the cerebral distribution of [Tc-99m]TRODAT-1 in healthy humans, Journal of Nuclear Medicine 40 (1999) 1812-1817.

[113] P.D. Mozley, H.J. Kim, R.C. Gur, K. Tatsch, L.R. Muenz, W.T. McElgin, M.P. Kung, M. Mu, A.M. Myers and H.F. Kung, [I-123]IPT SPECT imaging of CNS dopamine transporters: non-linear effects of normal aging on striatal uptake values, Journal of Nuclear Medicine 37 (1996), 1965-1970.

[114] P.D. Mozley, J.S. Schneider, P.D. Acton, E.D. Barraclough, M.B. Stern, K. Plossl, A. Alavi and H.F. Kung, Binding of [Tc-99m]TRODAT-1 to dopamine transporters in patients with Parkinson's disease and healthy volunteers, Journal of Nuclear Medicine in press, (1999).

[115] T. Muller, J. Farahati, W. Kuhn, E.G. Eising, H. Przuntek, C. Reiners and H.H. Coenen, [123I]beta-CIT SPECT visualizes dopamine transporter loss in de novo Parkinsonian patients, European Neurology 39 (1998), 44-48.

[116] M. Naumann, W. Pirker, K. Reiners, K. Langer, G. Becker and T. Brücke, [123I]beta-CIT single-photon emission tomography in DOPA-responsive dystonia, Movement Disorders 12 (1997), 448-451.

[117] J.L. Neumeyer, S-Y Wang, R.A. Milius, R.M. Baldwin, Y. Zea-Ponce, P.B. Hoffer, E. Sybirska, M.S. Al-Tikriti, D.S. Charney, R.T. Malison, M.A. Laruelle and R.B. Innis, [123I]2b-Carbomethoxy-3b-(4-iodophenyl)tropane: high-affinity SPECT radiotracer of monoamine reuptake sites in brain, Journal of Medicinal Chemistry 34 (1991), 3144-3146.

[118] T.G. Nygaard, Dopa-responsive dystonia: delineation of the clinical syndrome and clues to the pathogenesis, Advances in Neurology 60 (1993), 577-585.

[119] T.G. Nygaard, H. Takahashi, G.A. Heiman, B.J. Snow, S. Fahn and D.B. Calne, Long-term treatment response and fluorodopa positron emission tomographic scanning of parkinsonism in a family with dopa-responsive dystonia, Annals of Neurology 32 (1992), 603-608.

[120] N. Ogawa, Levodopa and dopamine agonists in the treatment of Parkinson's disease: advantages and disadvantages, European Neurology 34(3) (1994), 20-28.

[121] N. Ogawa, R. Edamatsu, K. Mizukawa, M. Asanuma, M. Kohno and A. Mori, Degeneration of dopaminergic neurons and free radicals. Possible participation of levodopa, Advances in Neurology 60 (1993), 242-250.

[122] M. Otsuka, Y. Ichiya, Y. Kuwabara, S. Hosokawa, M. Sasaki, T. Yoshida, T. Fukumura, M. Kato and K. Masuda, Glucose metabolism in the cortical and subcortical brain structures in multiple system atrophy and Parkinson's disease: a positron emission tomography study, Journal of the Neurological Sciences 144 (1996), 77-83.

[123] M. Otsuka, Y. Kuwabara, Y. Ichiya, S. Hosokawa, M. Sasaki, T. Yoshida, T. Fukumura, M. Kato and K. Masuda, Differentiating between multiple system atrophy and Parkinson's disease by positron emission tomography with $18 \mathrm{~F}$-dopa and 18F-FDG, Annals of Nuclear Medicine 11 (1997), 251-257.

[124] J. Owens, D.J. Wyper, J. Patterson, D.R. Brown, A.T. Elliott, G.M. Teasdale and J. McCulloch, First SPECT images of glutamate (NMDA) receptor activation in vivo in cerebral ischaemia, Nuclear Medicine Communications 18 (1997), 149-158.

[125] R. Pahwa, Progressive supranuclear palsy, Medical Clinics of North America 83 (1999), 369-379.

[126] M.I. Papp and P.L. Lantos, The distribution of oligodendroglial inclusions in multiple system atrophy and its relevance to the rate of clinical symptomatology, Brain 119 (1996), 235-243.

[127] Parkinson-Study-Group, Effects of tocopherol and deprenyl on the progression of disability in early Parkinson's disease, New England Journal of Medicine 328 (1993), 176-183.

[128] P. Piccini, D.J. Burn, R. Ceravolo, D. Maraganore and D.J. Brooks, The role of inheritance in sporadic Parkinson's disease: evidence from a longitudinal study of dopaminergic function in twins, Annals of Neurology 45 (1999), 577-582.

[129] P. Piccini, P.K. Morrish, N. Turjanski, G.V. Sawle, D.J. Burn, R.A. Weeks, M.H. Mark, D.M. Maraganore, A.J. Lees and D.J. Brooks, Dopaminergic function in familial Parkinson's disease: a clinical and 18F-dopa positron emission tomography study, Annals of Neurology 41 (1997), 222-229.

[130] M. Piert, R.A. Koeppe, B. Giordani, S. Minoshima and D.E. Kuhl, Determination of regional rate constants from dynamic FDG-PET studies in Parkinson's disease, Journal of Nuclear Medicine 37 (1996), 1115-1122.

[131] W. Pirker, S. Asenbaum, S. Wenger, J. Kornhuber, P. Angelberger, L. Deecke, I. Podreka and T. Brucke, Iodine-123epidepride-SPECT: studies in Parkinson's disease, multiple system atrophy and Huntington's disease, Journal of Nuclear Medicine 38 (1997), 1711-1717.

[132] P. Pollak, A.L. Benabid, P. Limousin, A. Benazzouz, D. Hoffman, J.F. Le Bas and J. Perret, Subthalamic nucleus stimulation alleviates akinesia and rigidity in parkinsonian patients, Advances in Neurology 69 (1996), 591-594.

[133] N. Quinn, Multiple system atrophy - the nature of the beast, Journal of Neurology, Neurosurgery and Psychiatry 52 (1989), 78-89.

[134] A.H. Raiput, B. Rozdilsky and A. Raiput, Accuracy of clinical diagnosis in parkinsonism - a prospective study, Canadian Journal of Neurological Science 12 (1991), 219-228.

[135] J.S. Rakshi, T. Uema and K. Ito, Statistical parametric mapping of three dimensional 18F-dopa PET in early and advanced Parkinson's disease (abstract), Movement Disorders 11 (1996), 147.

[136] R.J. Reiter, Oxidative damage in the central nervous system: protection by melatonin, Progress in Neurobiology 56 (1998), 359-384.

[137] P. Remy, Y. Samson, P. Hantraye, A. Fontaine, G. Defer, J.F. Mangin, G. Fenelon, C. Geny, F. Ricolfi and V. Frouin, Clinical correlates of $\left[{ }^{18} \mathrm{~F}\right]$ fluorodopa uptake in five grafted parkinsonian patinets, Annals of Neurology 38 (1995), 580588.

[138] J.O. Rinne, A. Laihinen, K. Nagren, H. Ruottinen, U. Ruotsalainen and U.K. Rinne, PET examination of the monoamine transporter with [11C]beta-CIT and [11C]beta-CFT in early Parkinson's disease, Synapse 21 (1995), 97-103.

[139] M.C. Rodriguez, J.A. Obeso and C.W. Olanow, Subthalamic nucleus-mediated excitotoxicity in Parkinson's disease: a target for neuroprotection, Annals of Neurology 44(1) (1998), S175-188. 
[140] M. Samuel, A.O. Ceballos-Baumann, N. Turjanski, H Boecker, A. Gorospe, G. Linazasoro, A.P. Holmes, M.R. DeLong, J.L. Vitek, D.G. Thomas, N.P. Quinn, J.A. Obeso and D.J. Brooks, Pallidotomy in Parkinson's disease increases supplementary motor area and prefrontal activation during performance of volitional movements an $\mathrm{H}_{2}$ (15)O PET study, Brain 120 (1997), 1301-1313.

[141] G.V. Sawle, P.M. Bloomfield, A. Bjorklund, D.J. Brooks, P. Brundin, K.L. Leenders, O. Lindvall, C.D. Marsden, S. Rehncrona and $\mathrm{H}$. Widner, Transplantation of fetal dopamine neurons in Parkinson's disease: PET [18F]6-L-fluorodopa studies in two patients with putaminal implants, Annals of Neurology 31 (1989), 166-173.

[142] G.V. Sawle, J.G. Colebatch, A. Shah, D.J. Brooks and C.D. Marsden, RSJ Frackowiak, Striatal function in normal aging: implications for Parkinson's disease, Annals of Neurology $\mathbf{2 8}$ (1990), 799-804

[143] G.V. Sawle, E.D. Playford, D.J. Burn, V.J. Cunningham and D.J. Brooks, Separating Parkinson's disease from normality: discriminant function analysis of [18F]Dopa PET data, Archives of Neurology 51 (1993), 2370-243.

[144] G.V. Sawle, S.J. Wroe, A.J. Lees, D.J. Brooks and R.S.J. Frackowiak, The identification of presymptomatic parkinsonism: clinical and [18F]-Dopa PET studies in an Irish kindred, Annals of Neurology 32 (1992), 609-617.

[145] A. Schrag, D. Kingsley, C. Phatouros, C.J. Mathias, A.J. Lees, S.E. Daniel and N.P. Quinn, Clinical usefulness of magnetic resonance imaging in multiple system atrophy, Journal of Neurology, Neurosurgery and Psychiatry 65 (1998), $65-71$.

[146] J.B. Schulz, T. Klockgether, D. Peterson, M. Jauch, W. Muller-Schauenburg, S. Spieker, K. Viogt and J. Dichgans, Multiple system atrophy: natural history, MRI morphology, and dopamine receptor imaging with 123IBZMSPECT, Journal of Neurology, Neurosurgery and Psychiatry 57 (1994), 1047-1056.

[147] J. Schwarz, K. Tatsch, T. Gasser, G. Arnold, O. Pogarell, G. Kunig and W.H. Oertel, 123I-IBZM binding compared with long-term clinical follow up in patients with de novo parkinsonism, Movement Disorders 13 (1998), 16-19.

[148] J.P. Seibyl, R.B. Innis, M.L. Early, B.A. Fussell and K. Marek, Baseline striatal dopamine transporter uptake measured with [I-123]beta-CIT may predict the rate of disease progression in idiopathic Parkinson's disease, Journal of $\mathrm{Nu}$ clear Medicine 5(1) (1999), 27.

[149] J.P. Seibyl, K.L. Marek, D. Quinlan, K. Sheff, S. Zoghbi, Y. Zea-Ponce, R.M. Baldwin, B. Fussell, E.O. Smith and D.S. Charney, Decreased single-photon emission computed tomographic [ ${ }^{123}$ I] beta-CIT striatal uptake correlates with symptom severity in Parkinson's disease, Annals of Neurology 38 (1995), 589-598

[150] M.L. Selley, (E)-4-hydroxy-2-nonenal may be involved in the pathogenesis of Parkinson's disease, Free Radical Biology and Medicine 25 (1998), 169-174.

[151] C-Y Shiue, J.S. Fowler, A.P. Wolf, D.W. McPherson, C.D. Arnett and L. Zecca, No-carrier-added fluorine-18-labeled $\mathrm{N}$-methylspiroperidol: synthesis and biodistribution in mice, Journal of Nuclear Medicine 27 (1986), 226-234.

[152] C.Y. Shiue, S. Vallabhahosula, A.P. Wolf, S.L. Dewey, J.S. Fowler, D.J. Schlyer, C.D. Arnett and Y.G. Zhou, Carbon-11 labelled ketamine-synthesis, distribution in mice and PET studies in baboon, Nuclear Medicine and Biology 24 (1997), 145-150.
[153] G.J. Siegel, B.W. Agranoff, R.W. Albers, S.K. Fisher and M.D. Uhler, Basic neurochemistry (sixth edition), Lippincot Williams \& Wilkins, Philadelphia, 1998.

[154] F.W. Smith, H.G. Gemmell, P.F. Sharp and J.A. Besson, Technetium-99m HMPAO imaging in patients with basal ganglia disease, British Journal of Radiology 61 (1988), 914920.

[155] B.J. Snow, T.G. Nygaard, H. Takahashi and D.B. Calne, Positron emission tomographic studies of dopa-responsive dystonia and early-onset idiopathic parkinsonism, Annals of Neurology 34 (1993), 733-738.

[156] B.J. Snow, I. Tooyama and E.G. McGeer, Human positron emission tomographic (fluorine-18)fluorodopa studies correlate with dopamine cell counts and levels, Annals of Neurology 34 (1993), 324-330.

[157] P.K. Sonsalla, D.S. Albers and G.D. Zeevalk, Role of glutamate in neurodegeneration of dopamine neurons in several animal models of parkinsonism, Amino Acids 14 (1998), 69-74.

[158] T. Subramanian, D.F. Emerich, R.A. Bakay, J.M. Hoffman, M.M. Goodman, T.M. Shoup, G.W. Miller, A.I. Levey, G.W. Hubert, S. Batchelor, S.R. Winn, J.A. Saydoff and R.L. Watts, Polymer encapsulated PC-12 cells demonstrate highaffinity uptake of dopamine in vitro and 18F-Dopa uptake and metabolism after intracerebral implantation in nonhuman primates, Cell Transplantation 6 (1997), 469-477.

[159] K. Tatsch, J. Schwarz, P.D. Mozley, R. Linke, O. Pogarell, W.H. Oertel, R.S. Fieber, K. Hahn and H.F. Kung, Relationship between clinical features of Parkinson's disease and presynaptic dopamine transporter binding assessed with [123I]IPT and single-photon emission tomography, European Journal of Nuclear Medicine 24 (1997), 415-421.

[160] K. Tatsch, J. Schwarz, W.H. Oertel and C-M Kirsch, SPECT imaging of dopamine $D_{2}$ receptors with $\left[{ }^{123} \mathrm{I}\right] \mathrm{IBZM}$ in Parkinsonian syndromes, Journal of Nuclear Medicine 32 (1991), 1014-1015.

[161] D. Testa, G. Filippini, M. Farinotti, E. Palazzini and T. Caraceni, Survival in multiple system atrophy: a study of prognostic factors in 59 cases, Journal of Neurology $\mathbf{2 4 3}$ (1996), 401-404.

[162] J.W. Tetrud and J.W. Langston, The effect of deprenyl (selegiline) on the natural history of Parkinson's disease, Science 245 (1989), 519-522.

[163] G. Tissingh, P. Bergmans, J. Booij, A. Winogrodzka, E.A. van Royen, J.C. Stoof and E.C. Wolters, Drug-naive patients with Parkinson's disease in Hoehn and Yahr stages I and II show a bilateral decrease in striatal dopamine transporters as revealed by [123I]beta-CIT SPECT, Journal of Neurology 245 (1998), 14-20.

[164] G. Tissingh, J. Booij, A. Winogrodzka, E.A. van Royen and E.C. Wolters, IBZM-and CIT-SPECT of the dopaminergic system in parkinsonism, Journal of Neural Transmission $\mathbf{5 0}$ (1997), S31-S37.

[165] E. Van Royen, N.F.L.G. Verhoeff, J.D. Speelman, E.C. Wolters, M.A. Kuiper and A.G.M. Janssen, Multiple system atrophy and progressive supranuclear palsy. Diminished striatal D2 receptor activity demonstrated by 123IBZM single photon emission computed tomography, Archives of Neurology 50 (1993), 513-516.

[166] C.H. Vandyck, J.P. Seibyl, R.T. Malison, M. Laruelle, E. Wallace, S.S. Zoghbi, Y. Zea-Ponce, R.M. Baldwin, D.S. Charney, P.B. Hoffer and R.B. Innis, Age-related decline in striatal dopamine transporter binding with iodine-123-beta- 
CIT SPECT, Journal of Nuclear Medicine 36 (1995), 11751181.

[167] F.J.G. Vingerhoets, B.J. Snow, S. Lee, M. Schultzer, E. Mak and D.B. Calne, Longitudinal fluorodopa positron emission tomographic studies of the evolution of idiopathic parkinsonism, Annals of Neurology 36 (1994), 759-764.

[168] F.J.G. Vingerhoets, B.J. Snow, J.W. Tetrud, J.W. Langston, M. Schulzer and D.B. Calne, Positron emission tomographic evidence for progression of human MPTP-induced dopaminergic lesions, Annals of Neurology 36 (1994), 765-770.

[169] N.D. Volkow, Y.S. Ding, J.S. Fowler, G.J. Wang, J. Logan, S.J. Gatley, R. Hitzemann, G. Smith, S.D. Fields and R. Gur, Dopamine transporters decrease with age, Journal of Nuclear Medicine 37 (1996), 554-559.

[170] N.D. Volkow, Y.S. Ding, J.S. Fowler, G.J. Wang, J. Logan, S.J. Gatley, D.J. Schlyer and N. Pappas, A new PET ligand for the dopamine transporter: studies in the human brain, Journal of Nuclear Medicine 36 (1995), 2162-2168.

[171] N.D. Volkow, J.S. Fowler, G-J Wang, J. Logan, D.J. Schyler, R.R. Macgregor, R. Hitzemann and A.P. Wolf, Decreased dopamine transporters with age in healthy human subjects, Annals of Neurology 36 (1994), 237-239.

[172] S.J. Wang, R.S. Liu, H.C. Liu, K.N. Lin, D.E. Shan, K.K. Liao, J.L. Fuh and L.S. Lee, Technetium-99m hexamethylpropylene amine oxime single photon emission tomography of the brain in early Parkinson's disease: correlation with dementia and lateralization, European Journal of Nuclear Medicine 20 (1993), 339-344.

[173] C.D. Ward, R.C. Duvoisin, S.E. Ince, J.D. Nutt, R. Eldridge and D.B. Calne, Parkinson's disease in 65 pairs of twins and in a set of quadruplets, Neurology 33 (1983), 815-824.

[174] G.K. Wenning, E. Donnemiller, R. Granata, G. Riccabona, W. Poewe, 123I-beta-CIT and 123I-IBZM SPECT scanning in levodopa-naive Parkinson's disease, Movement Disorders 13 (1998), 438-445.

[175] L. Zou, J. Jankovic, D.B. Rowe, W. Xie, S.H. Appel and W. Le, Neuroprotection by pramipexole against dopamineand levodopa-induced cytotoxicity, Life Sciences 64 (1999), 1275-1285. 


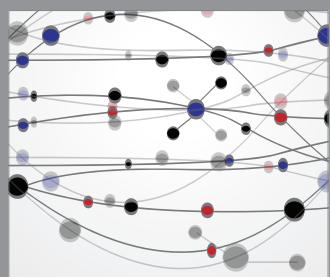

The Scientific World Journal
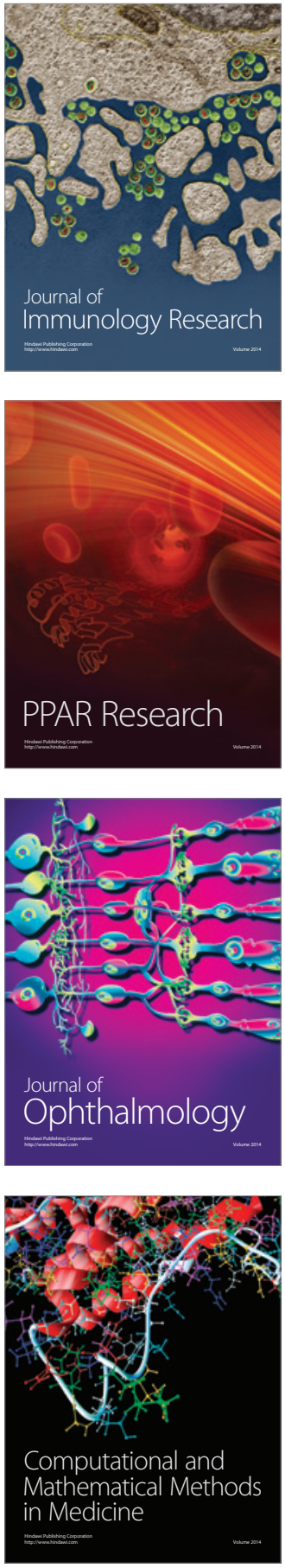

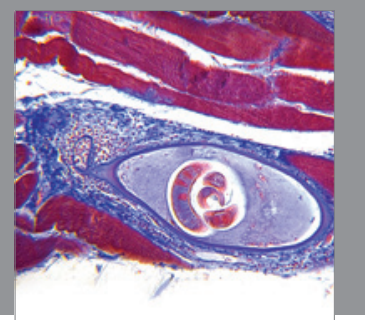

Gastroenterology

Research and Practice
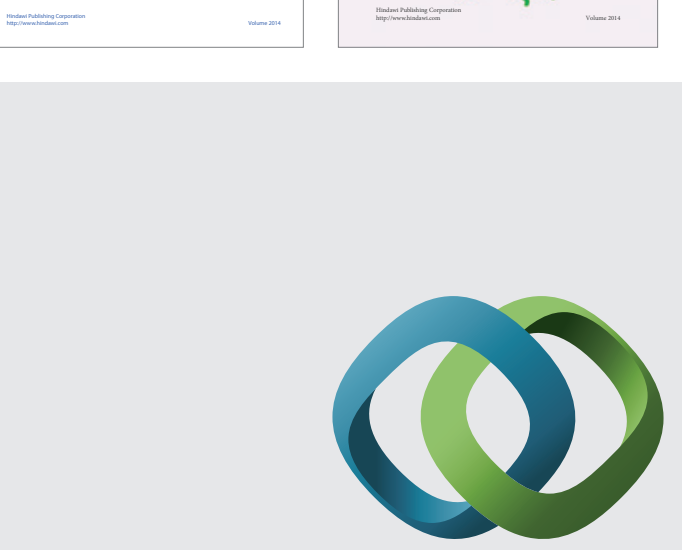

\section{Hindawi}

Submit your manuscripts at

http://www.hindawi.com
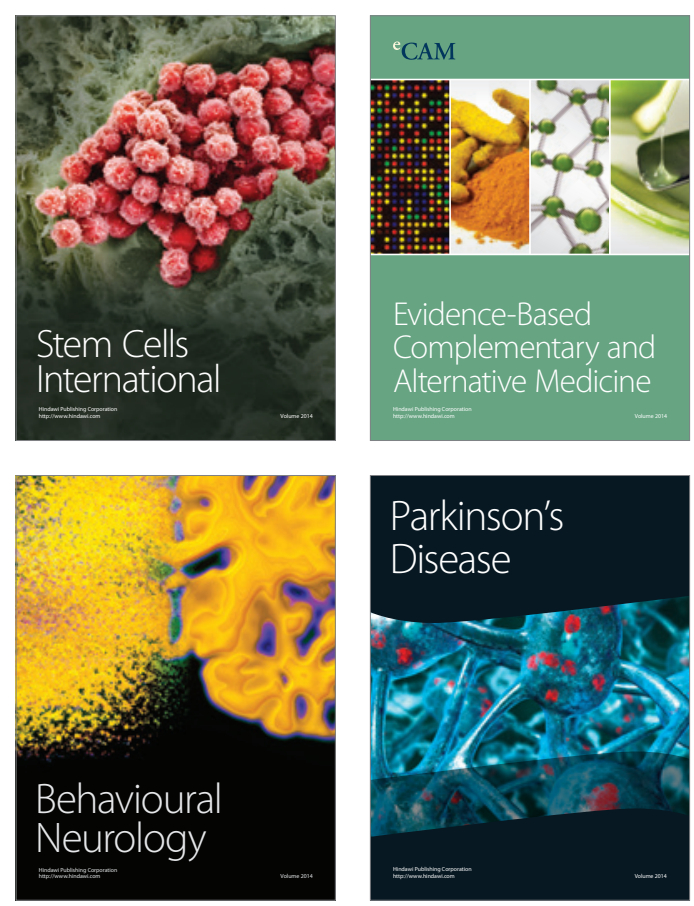

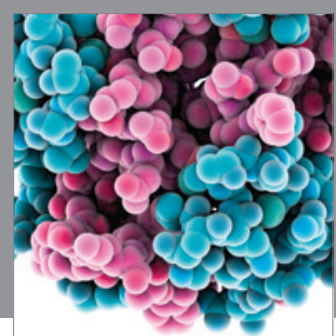

Journal of
Diabetes Research

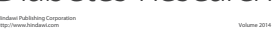

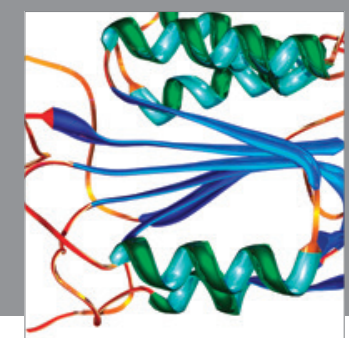

Disease Markers
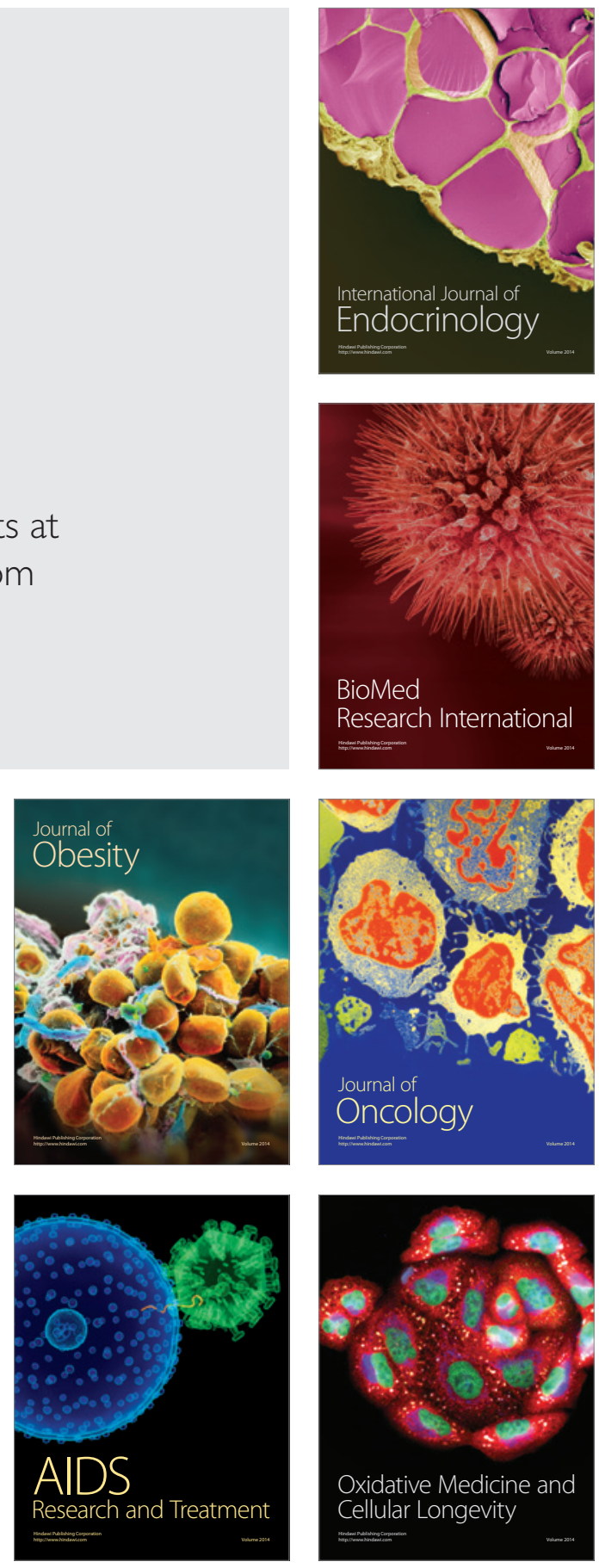